\title{
WORK LOCUS OF CONTROL AS A MODERATOR OF THE RELATIONSHIP BETWEEN WORK STRESSORS AND COUNTERPRODUCTIVE WORK BEHAVIOR
}

\author{
Justin M. Sprung
}

\author{
A Thesis \\ Submitted to the Graduate College of Bowling Green \\ State University in partial fulfillment of \\ the requirements for the degree of
}

\section{MASTER OF ARTS}

December 2011

Committee:

Steve M. Jex, Advisor

Michael J. Zickar

Anne K. Gordon 
(C) 2011

Justin Sprung

All Rights Reserved 


\section{ABSTRACT}

Steve M. Jex, Advisor

The current study was conducted in order to determine whether work locus of control serves as a moderator of the relationship between work stressors and counterproductive work behavior. In order to examine this relationship, 208 full-time working adults employed in various occupations were surveyed via an online database. Using hierarchical regression analyses, both main and moderator effects were tested in order to determine whether work locus of control influences employees' tendency to engage in counterproductive behavior in response to work stressors. Results indicate that work locus of control significantly interacted with work stressors in predicting counterproductive work behavior, suggesting work locus of control as an important variable to consider in counterproductive work behavior research. Implications of these findings, as well as future research ideas, are discussed. 
Dedication

To my mom and dad...

None of this would be possible without you. 


\section{ACKNOWLEDGMENTS}

The completion of this thesis would not have been possible without the support and mentorship of several people. I am extremely grateful to my advisor, Steve Jex, for his patience, encouragement, and guidance throughout this process. I would also like to extend a sincere thanks to my committee members, Mike Zickar and Anne Gordon, for their insightful comments, feedback, and advice. Next, I would like to thank Mike Sliter and Chris Lake for their assistance and recommendations during the multiple stages of this process. Finally, I would like to thank all of my friends and family for their support over the past year. 


\section{TABLE OF CONTENTS}

Page

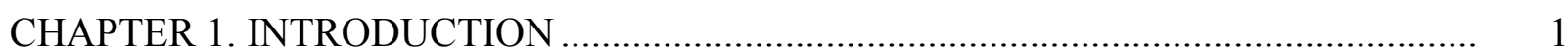

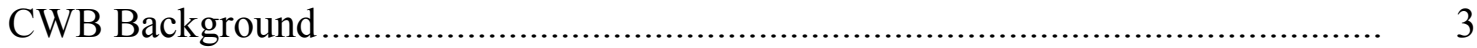

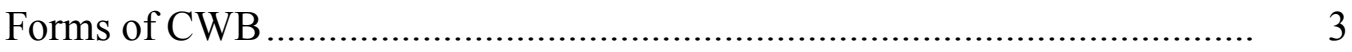

Antecedents of CWB ........................................................................ 5

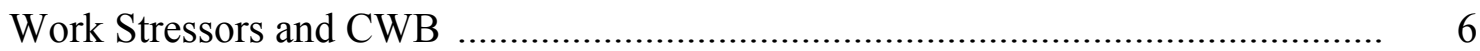

Interpersonal Stressors and CWB .................................................. 6

Organizational Stressors and CWB ............................................... 11

Work Stressor Hypotheses .......................................................... 15

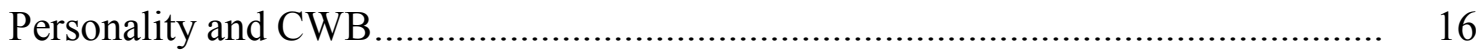

Five-Factor Model and CWB......................................................... 16

Individual Personality Traits and CWB ............................................... 18

Work Locus of Control ........................................................................... 19

Work Locus of Control and CWB .................................................. 21

Work Locus of Control as a Moderator ................................................... 22

CHAPER 2. METHOD ........................................................................................ 26

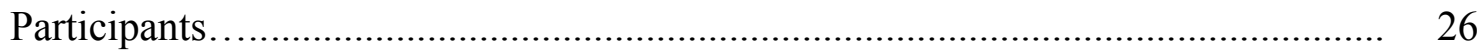

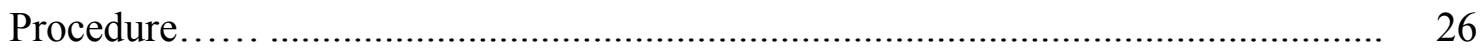

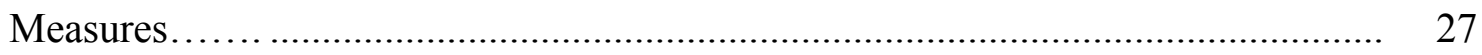

Organizational Constraints............................................................... 27

Interpersonal Conflict ............................................................... 27

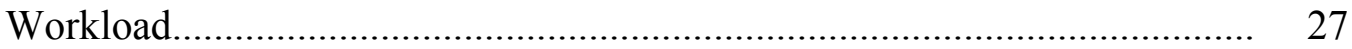


Organizational Justice ................................................................ 28

Work Locus of Control ...................................................................... 28

Frustration ............................................................................... 28

Counterproductive Work Behavior....................................................... 29

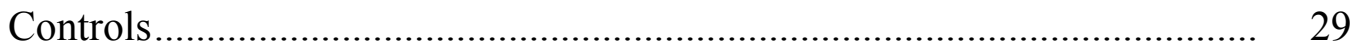

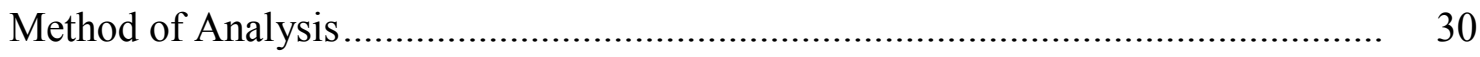

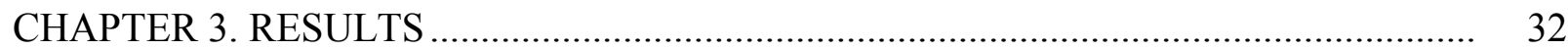

Main Effect Hypotheses......................................................................... 33

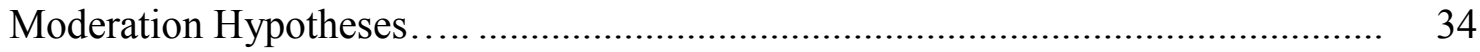

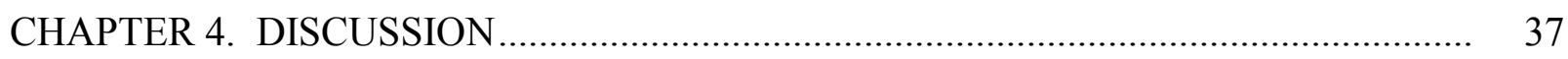

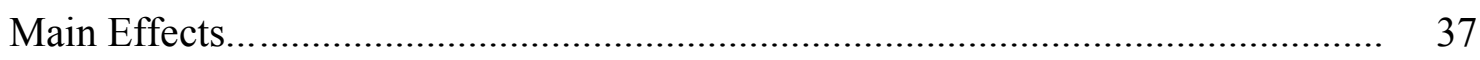

Interactive Effects of Work Stressors and Work Locus of Control ........................ 40

Practical Implications.......................................................................... 43

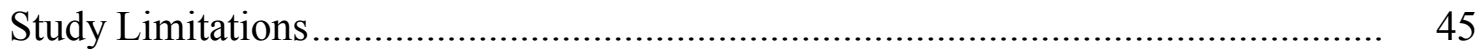

Future Directions ............................................................................... 47

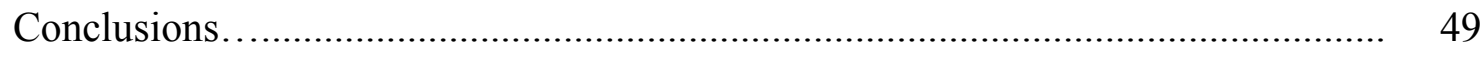

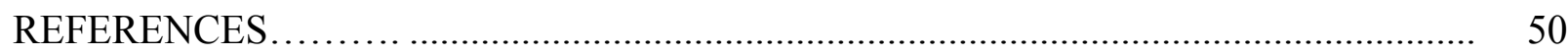

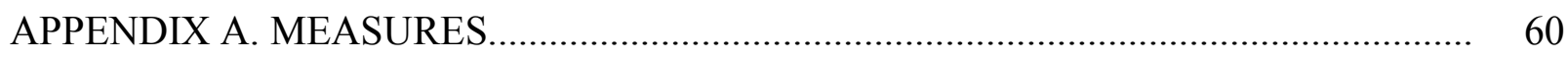

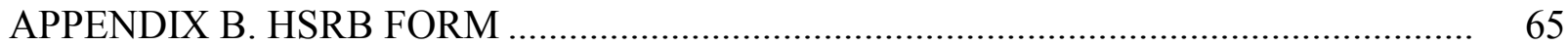




\section{LIST OF TABLES}

Table

Page

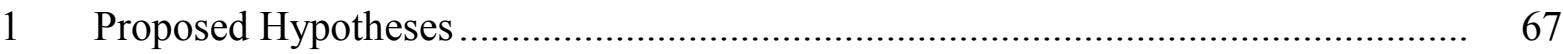

2 Descriptive Statistics and Internal Consistencies ............................................ 68

$3 \quad$ Intercorrelations among Variables ............................................................ 69

4 Moderated Regression Results: Work LOC as a Moderator of the Relationship between

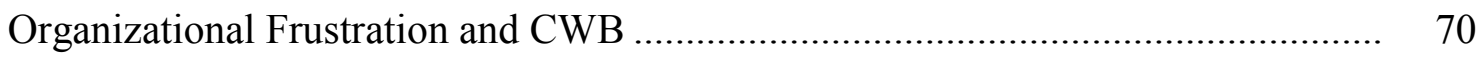

5 Moderated Regression Results: Work LOC as a Moderator of the Relationship between Organizational Constraints and CWB........................................................ 71

6 Moderated Regression Results: Work LOC as a Moderator of the Relationship between Interpersonal Conflict and CWB ......................................................... 72

7 Moderated Regression Results: Work LOC as a Moderator of the Relationship between

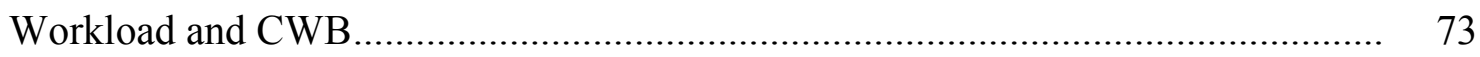

8 Moderated Regression Results: Work LOC as a Moderator of the Relationship between

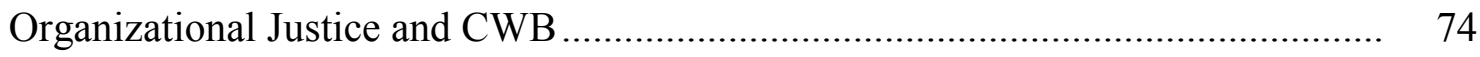




\section{LIST OF FIGURES}

Figure $\quad$ Page

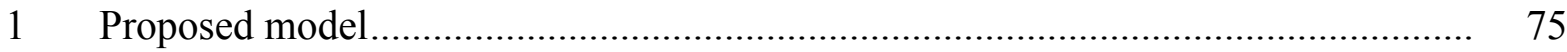

2 The moderating effect of work locus of control on the relationship between organizational constraints and counterproductive work behavior ........................ 76

3 The moderating effect of work locus of control on the relationship between interpersonal conflict and counterproductive work behavior ............................................. 77

4 The moderating effect of work locus of control on the relationship between organizational justice and counterproductive work behavior ............................ 78 


\section{CHAPTER 1. INTRODUCTION}

Counterproductive work behavior (CWB) refers to intentional behavior by employees that harms or intends to harm organizations and/or organizational members (Rotundo \& Spector, 2010). These behaviors can take a variety of forms, including (but not limited to): aggression, interpersonal conflict, sabotage, theft, wasting time and/or materials, spreading rumors, refusing to cooperate, and physical assault (Penny \& Spector, 2002; Gruys \& Sackett, 2003 ). Because of the multitude of behaviors that are classified as CWBs, these behaviors have been studied under a variety of terms, including antisocial workplace behavior, organizational delinquency, and workplace deviance, to name only a few (Penney \& Spector, 2005). Though the terminology may differ from study to study, the majority of these deviant behaviors can be subsumed under the broader construct of CWB.

Counterproductive work behavior can be distinguished from other potentially deviant behaviors in two ways: 1) CWB is volitional, and 2) CWB has harmful intentions. Therefore, CWB does not include behaviors that are accidental or behaviors that are not under a person's control. For example, an employee absence due to sickness and/or family matters would not be classified as CWB, while an employee absence simply to spite a coworker/supervisor would be considered CWB. While any absence has potential negative consequences, the difference between these two actions is that the former is unintentional while the latter possesses harmful intentions. Similarly, poor performance would not be considered a CWB if an employee is putting forth effort to complete job tasks but simply lacks the ability to do so, as opposed to a situation where an employee is purposely slowing down his/her work (Rotundo \& Spector, 2010). 
The wide variety of behaviors within the construct of CWB encompasses many potential challenges for organizations. Previous research has demonstrated the significance of CWB, illuminating that these behaviors are detrimental to organizations as well as the people associated with the organizations. For example, some researchers have found that up to $75 \%$ of employees steal from their employer at least once (McGurn, 1988), while others propose that $95 \%$ of organizations are targets of employee theft and fraud (Mount, Ilies, \& Johnson, 2006). Furthermore, another study reported that $68 \%$ of managers expressed that they experienced verbal forms of aggression (e.g. insults, profanity) from employees in response to negative performance evaluations (Neuman \& Baron, 1998). In addition to organizational members, consumers and stakeholders may also feel the negative effects of CWB through higher prices on goods and services (Rotundo \& Spector, 2010). Thus, CWB can have a variety of negative effects involving nearly every person associated with an organization.

Regarding literal cost to organizations, it has been suggested that CWB can cost American businesses up to $\$ 200$ billion annually (Penney \& Spector, 2002). It has even been projected that these behaviors may cost the average business between $1 \%$ and $2 \%$ of annual sales, and may account for as many as $20 \%$ of failed businesses (Coffin, 2003). Consequently, CWBs have the potential to inflict severe damage upon entire organizations. Due to the prevalence and implications associated with these behaviors, it is important to understand the factors that influence employees' likelihood of engaging in CWB.

Previous research has revealed work stressors and personality as two important variables to consider when examining CWB. Work stressors have repeatedly been shown to relate to the occurrence of deviant behavior (e.g. Fox, Spector, \& Miles, 2001; Penney \& Spector, 2005) and are established as a primary antecedent of CWB. Personality has also been shown to be 
associated with a person's propensity to engage in CWB (Mount et al., 2006; Salgado, 2002).

These two variables are related because personality may influence the way in which employees interpret and respond to work stressors. Accordingly, recent research has suggested personality as a potential moderator in the relationship between work stressors and CWB (e.g. Bowling \& Eschleman, 2010). Therefore, it is important to examine the interactive effects of work stressors and personality on CWB.

The present study seeks to extend this area of research by examining a relatively novel personality trait - work locus of control (LOC) - in relation to CWB. Specifically, this study examines the main effect of work LOC, as well as the interactive effects of work LOC and work stressors, in predicting CWB. This study is beneficial in that it provides further information regarding how personality, specifically work locus of control, may influence the relationship between work stressors and CWB.

\section{CWB Background}

\section{Forms of $C W B$}

The first systematic attempts at categorizing CWB involved Hollinger and Clark's (1983) distinction between two types of behavioral dimensions: property deviance and production deviance (Sackett, 2002). Property deviance refers to misuse of employer assets, including actions such as theft and property damage, while production deviance involves violation of norms regarding how work should be accomplished, such as wasting time and/or alcohol abuse (Sackett, 2002). This categorization was useful as a starting point; however, it was not a comprehensive classification system for all forms of CWB. That is, not all deviant behaviors fit clearly into these two categories. 
More recently, Robinson and Bennett (1995) expanded the categorization by including interpersonal CWB. They developed a typology distinguishing between behaviors directed toward the organization (CWB-O) and interpersonal behaviors directed towards other people (CWB-I), acknowledging that CWB can also be interpersonally oriented. As with organizational counterproductive behavior, interpersonal counterproductive behaviors can take a variety of forms, ranging from minor acts such as gossiping about coworkers and showing favoritism, to more extreme forms such as sexual harassment and verbal abuse. Therefore, CWB can take multiple forms.

The authors later established evidence in support of their CWB model (Bennett \& Robinson, 2000). Specifically, the results from their confirmatory factor analysis verified two distinct scales within the CWB construct. Although the two dimensions were related to each other, with a correlation of 46 between CWB-I and CWB-O, the two dimensions were shown to reflect different aspects within CWB. Additionally, Gruys and Sackett (2003) found evidence in support of the categorical distinction between interpersonal and organizational forms of CWB among 11 dimensions of CWB. As with Bennett and Robinson (2000), these authors also found evidence of correlated $(r=.43)$ but distinct dimensions through the use of confirmatory and exploratory factor analysis procedures. Thus, although there may be a general underlying factor of CWB, focusing on a single dimension of CWB may not tell the whole story; because the forms of CWB target different entities, each form may have differing antecedents. Therefore, it seems appropriate to separate CWB into interpersonal and organizational dimensions.

One of the most recent conceptualizations of CWB is provided by Spector, Fox, Penney, Bruursema, Goh, and Kessler (2006). These authors agree that the behaviors subsumed by CWB are too diverse to be represented by a single construct because the CWB items were differentially 
associated with antecedents; for example, some items related more strongly to anger and stress, while others associated more strongly with boredom. Accordingly, Spector and colleagues developed a scale separating CWB into two dimensions: CWB-I and CWB-O. In addition, the authors further divide CWB into five sub-dimensions: abuse (harmful behaviors directed towards other people), production deviance (purposely doing work incorrectly or slowly), sabotage (physical destruction/vandalism of employer property), theft (stealing property from people or organization), and withdrawal (working fewer hours than required). The CWB-I dimension contains mostly items within the abuse sub-dimension, while CWB-O contains items from the other four subscales. Thus, it is important to understand that CWB can be broken down into different dimensions and that these categories may have differing antecedents. This is relevant to the present study in that work stressors may be differentially related to the CWB-I and CWB-O dimensions. Regardless of how one conceptualizes CWB, there have been a variety of variables found to be associated with the likelihood of engaging in CWB.

\section{Antecedents of $C W B$}

Previous research has revealed various potential antecedents of CWB, ranging from personal and organizational variables ( $\mathrm{Lau}, \mathrm{Au}, \& \mathrm{Ho}, 2003$ ) to motivation and control variables (Marcus \& Schuler, 2004). Among these antecedents, various individual differences have been found to be associated with CWB, including demographic variables (Berry, Ones, \& Sackett, 2007; Lau et al., 2003), job attitudes (Dalal, 2005; Hershcovis et al., 2007), emotions (Miles, Borman, Spector, \& Fox, 2002; Spector \& Fox, 2002), and personality (Salgado, 2002; Mount et al., 2006). In addition, environmental factors such as leadership style (Hepworth \& Towler, 2004), abusive supervision (Tepper, 2007), workplace incivility (Penney \& Spector, 2005), organizational justice (Dalal, 2005; Greenberg, 1990), coworker influence (Robinson \& 
O’Leary-Kelly, 1998), and work stressors (Chen \& Spector, 1992) have also been shown to be related to the occurrence of CWB. Thus, there are multiple predictors of CWB.

Of the antecedents shown to be associated with CWB, work stressors and personality have garnered the attention of much previous research, demonstrating both direct and interactive effects on CWB. Accordingly, work stressors and personality are the focus of the present study. In order to provide a background for the current study, work stressor and personality research relevant to the CWB literature will be reviewed, followed by a review of the potential interactive effects of work stressors and personality on CWB.

\section{Work Stressors and CWB}

The environment in which an employee works encompasses many variables that may have a substantial impact on employee likelihood of engaging in CWB. Of the antecedents associated with CWB, work stressors seem to be among the most prevalent. Work stressors refer to taxing aspects of a job, including employee workload, interpersonal conflict, and organizational constraints (Spector \& Jex, 1998). Sonnentag and Frese (2003) reported that between 26 and 40 percent of all surveyed workers experience their work as very stressful. Given the prevalence of stressors in general, it is important to examine work stressors in relation to CWB. Previous research has identified numerous potential negative outcomes associated with stress for both people and organizations, one of which is CWB. Various forms of work stressors have been shown to be positively related to CWB (Rotundo \& Spector, 2010), including interpersonal and organizational stressors, which will be discussed in turn.

\section{Interpersonal Stressors and CWB}

Interpersonal stressors involve stressful social situations with one or more people in the workplace. One stressor that has been shown to be related to CWB is interpersonal conflict, 
which refers to the experience of disagreements and/or poor treatment at work. This can be covert (e.g. spreading rumors about someone) or overt (e.g. being rude to a coworker) and can range from minor disagreements to physical assault (Spector \& Jex, 1998). Interpersonal conflict can be distinguished from CWB-I in that CWB-I is intended to harm the target whereas interpersonal conflict does not necessarily have harmful intentions. For example, two coworkers may have differing opinions on how to perform a certain job task, leading to conflict as to which person's method is better. In this situation, the two coworkers are not necessarily intending to harm each other, but rather having a simple disagreement. However, interpersonal conflict and disagreements may escalate and potentially lead to forms of CWB. As such, previous research has discovered a link between interpersonal conflict and CWB-I.

Fox et al. (2001) found that interpersonal conflict significantly predicted both CWB-I and CWB-O. This study also examined the mediating role of negative emotions in the relationship between conflict and CWB. It was found that interpersonal conflict was significantly related to negative emotions, and that negative emotions were positively related to both forms of CWB. Thus, the results suggested negative emotions as a means by which interpersonal conflict may lead to CWB. Accordingly, people who experience interpersonal conflict may subsequently experience more negative emotions, such as anger or anxiety. These negative emotions, in turn, may contribute to increases in CWB. For example, conflict with another person may lead an employee to experience the negative emotion of anger, and the employee may release this anger through engaging in destructive acts against the organization or the perpetrator of the conflict. Thus, CWB may serve as an action by which employees release the tension created by negative emotions. These results suggest that emotions play a significant role in the process by which stressors lead to CWB. 
Affective events theory (AET) may provide a theoretical explanation as to how work stressors may lead to CWB through emotions. According to AET, events serve as proximal causes of affective reactions (Weiss \& Cropanzano, 1996). In other words, incidents happen to people while at work and people react emotionally to these events. Therefore, emotional experiences can lead to behavioral reactions. Thus, in terms of interpersonal conflict, the work event (conflict) may lead to a negative emotional reaction (anger). This emotional reaction may, in turn, serve as the reason why an employee engages in CWB. More specifically, the employee may engage in CWB as a way to release his/her negative emotions stemming from a work stressor - in this case, interpersonal conflict. As such, AET provides a compelling framework indicating that CWB may be at least partially a result of emotional reactions to work stressors. More recently, a model specific to CWB has been developed to demonstrate the role of emotions in the relationship between stressors and CWB. Fox and Spector (2006) have proposed a stressor-emotion theory of CWB suggesting that emotions play a central role in the process by which stressors lead to CWB. Specifically, the model proposes that stressors trigger negative emotions, which then increase the likelihood that employees will engage in CWB. Therefore, various work stressors may lead to the experience of negative emotions; similar to AET, these negative emotions serve as a mechanism linking stressors to CWB. Fox and Spector (1999) also developed a work frustration-aggression model (Fox \& Spector, 1999) to help explain the process by which work events lead to CWB. This model suggests that affective reactions mediate the relationship between frustrating work events and CWB. Thus, frustrating work events may lead to strong affective reactions, which in turn can lead to CWB. As such, emotions such as anger and frustration both seem to play a role in the relationship between stressors and CWB. 
Hershcovis and colleagues (2007) conducted a meta-analysis and found results similar to Fox and colleagues (2001); interpersonal conflict among employees was positively correlated with both forms of CWB. Moreover, they found that the correlation between conflict and CWB-I was significantly larger than the correlation between conflict and CWB-O. Thus, employees experiencing interpersonal conflict may be more likely to engage in interpersonal forms of CWB. This suggests that, in many cases, CWB may be used as a means of retaliation. It also may be that CWB occurs as a result of people displacing their aggressions onto others. People who feel they have been treated unfairly may desire revenge, which can be accomplished by punishing the person(s) blamed for the problem/conflict (Skarlicki \& Folger, 1997). For example, an employee experiencing conflict with another organizational member is probably more likely to engage in CWB against that person rather than the organization as a whole. This allows the employee to "get back" at the person(s) with whom the conflict was with. Greater likelihood of CWB-I makes logical sense in that retaliation against the organization would not necessarily have a direct consequence on the person with whom the conflict was with originally; retaliation against the perpetrator, however, seems more likely to be perceived as evening things up between the two people and potentially defending the target from future conflicts.

The previous studies suggest that different stressors may have differential relations with the types of CWB one engages in. Moreover, the study conducted by Skarlicki and Folger (1997) also seems to demonstrate the spiraling effect of incivility presented by Andersson and Pearson (1999), whereby workplace incivility (mild forms of rude and discourteous behavior) can spiral into increasingly intense and aggressive behavior. For example, one mild act of CWB (i.e. rude comments) can potentially escalate into subsequent acts of more aggressive forms of CWB (i.e. physical assault). As a result, people may continually try to get even with the perpetrator. As 
such, this study represents another mechanism by which work stressors may lead to CWB: restoration of equity.

Restoration of equity, in addition to negative emotions, helps to explain the link between stressors and CWB. According to equity theory (Adams, 1963), fairness in social relationships occurs when rewards, punishments, or resources are allocated proportionally to one's contributions. Applied to a working context, employees who experience high levels of stress may see themselves as putting forth greater amounts of mental or physical effort in comparison to their coworkers and/or supervisors, yet get paid the same (or less). In this case, employees may not view their reward as proportional to their contributions to the organization, resulting in perceptions of inequity. A person who experiences inequity may act out in order to restore equity (Spector \& Fox, 2002). Therefore, perceptions of inequity may serve as a mediating mechanism by which work stressors can lead to CWB. Work stressors may lead an employee to perceive a sense of inequity, which may then cause the employee to act out against another person or the organization in order to restore feelings of equity. As a result, CWB can be used as a means to keep things fair/even between an employee and the organization.

Related to Hershcovis and colleagues (2007), others have found that the status of the person with whom the employee has conflict with (i.e., the perpetrator) is likely to affect the target of CWB. Bruk-Lee and Spector (2006) examined the differential impact of employee conflict with supervisors compared to employee conflict with coworkers. Results suggested that the source of the employees' conflict does play a role in determining the target of their CWB. Specifically, conflict with coworkers was associated with more CWB-I while conflict with supervisors led to more CWB-O. Bruk-Lee and Spector (2006) theorized that people who have conflict with their supervisor were more likely to direct their CWB at the organization because 
the supervisor is seen as an agent of the organization; targeting the organization is much safer for the employee than retaliating against a supervisor. Though the employee is not retaliating directly against the person with whom the conflict was with, the employee is still able to achieve/perceive retribution indirectly by potentially harming the organization. Taking one's frustration with a supervisor out on the organization is less visible than engaging in CWB directly against the supervisor, and thus, less likely to lead to negative consequences.

Additionally, retaliation against the organization may be more easily accessible for the employee than retaliation against a supervisor. This study demonstrates that the type of CWB one engages in may differ depending on who the source of the conflict is.

The results of the previous studies demonstrate the important concept that the type of stressor an employee experiences, and/or the perpetrator of the conflict, may impact the target of CWB. Some stressors may lead to CWB-I while others may lead to CWB-O. Though the previous studies focused on interpersonal conflict, the results that interpersonal conflict demonstrated a significantly higher correlation with CWB-I suggests that stressors dealing with the organization, such as organizational constraints, may be more likely to lead to CWB-O. As a result, different stressors may have differential associations with employees' tendencies to engage in CWB-I versus CWB-O.

\section{Organizational Stressors and CWB}

In addition to interpersonal stressors, aspects of the environment stemming from the organization as a whole can also impact employee stress levels and reactions to these stressors. One aspect stemming from the organization that can be perceived as a stressor is organizational constraints. These refer to situations or aspects of the work environment that interfere with employee job performance, such as poor equipment, incomplete information, or interruption by 
others (Spector \& Jex, 1998). Previous research has demonstrated that organizational constraints are significantly related to both CWB-I and CWB-O (e.g. Fox et al., 2001; Penney \& Spector, 2005). Moreover, it has been found that organizational constraints tend to be more strongly related to CWB-O, suggesting that organizational constraints may lead to more CWB directed at the organization than at other people (Fox et al., 2001; Hershcovis et al., 2007). This is consistent with the idea that interpersonal conflict is more strongly associated with CWB-I. Because the source of the stress is stemming from the organization, employees are likely to retaliate against the organization rather than against other people.

As with interpersonal conflict, negative emotions were also found to have a mediating effect on the relationship between organizational constraints and CWB (Fox et al., 2001). Organizational constraints tend to be positively associated with negative emotions, which in turn are associated with increased CWB. As mentioned previously, AET may help to explain this relationship. In this case, organizational constraints may lead to negative emotional reactions (i.e. anger), and these negative emotions can contribute to counterproductive behavioral reactions. In other words, CWB may serve as a means by which negative emotions can be released. For example, in response to experiencing anger as a result of organizational constraints, an employee may release that anger by spreading rumors about his/her organization and/or steal property from the organization. Thus, emotions seem to play an important role in the relationship between both interpersonal and organizational forms of work stressors and CWB.

Another organizational variable that has been proposed to have an impact on CWB is organizational injustice (employee perceptions of fairness). Fox et al. (2001) point out that employee perceptions of injustice can be conceptualized as a form of perceived job stress that can lead to CWB. Many studies have examined the negative consequences of employee 
perceptions of injustice. Greenberg (1990) conducted a field study involving manufacturing employees receiving pay cuts. Employees who received an inadequate explanation for the pay cut experienced greater perceptions of pay inequity and had higher theft rates than those who received a more thorough explanation for the pay cut. Thus, employee perceptions of organizational (in)justice are important and can play a role in the likelihood of engaging in CWB. For the employees in Greenberg's study, theft was seen as a way to restore justice between themselves and the organization. Because they did not feel they were treated fairly, they felt that theft was an appropriate means of "evening things up." Accordingly, if employees feel like they are treated unfairly, they may engage in more CWB against the organization in order to make things equal between themselves and their organization. Thus, restoration of equity serves as a mechanism by which organizational justice can lead to CWB-O.

A more recent form of CWB is cyberloafing, which refers to employees using their company's internet for personal use during work hours; this too has been shown to be related to perceived organizational injustice (Lim, 2002). Lim conducted an online survey to assess the relationship between organizational justice and cyberloafing. The results suggest that employees who experience greater levels of injustice were more likely to engage in cyberloafing. It was concluded that the employees' perceived injustice served as a reason to legitimize their engagement in cyberloafing. As with theft in the Greenberg (1990) study, cyberloafing was seen by employees as an acceptable way of dealing with the perceived stressor of injustice because it led to a perceived restoration of justice. Multiple meta-analyses have also found a significant negative relationship between organizational injustice and CWB (Dalal 2005; Cohen-Charash \& Spector, 2001). Accordingly, employee perceptions of justice involving treatment, outcomes, and 
procedures to determine those outcomes can have a significant impact on employees' likelihood of engaging in CWB.

In addition to organizational constraints and organizational injustice, workload represents another organizational stressor that may contribute to CWB. Chen and Spector (1992) found that employee workload can lead to an increased likelihood of engaging in CWB. This could be due to employee feelings of frustration (i.e. work-frustration-aggression model; Fox \& Spector, 1999). For example, the greater workload employees have, the more likely they are to feel overwhelmed as a result of their situation. Going back to AET, employees' workload can lead to negative emotional reactions such as anger, frustration, or even neglect from their organization. These negative emotional reactions may increase their likelihood of engaging CWB. This shows that even something as simple as the amount of work/tasks one has to do on the job may play a role in the amount of $\mathrm{CWB}$ an employee engages in.

As described above, there is evidence suggesting different paths leading to CWB. For example, interpersonal conflict may lead to more CWB-I while organizational constraints may lead to greater levels of CWB-O. Though work stressors can be separated into interpersonal and organizational domains, the mechanisms by which both types of stressors lead to CWB seem similar. Regardless of the type of work stressor, previous research has demonstrated that negative emotions and restoration of equity both seem to play a role in the relationship between various work stressors and both forms of CWB (e.g. Fox et al., 2001; Greenberg, 1990; Fox \& Spector, 1999). Thus, negative emotions and restoration of equity serve as important mechanisms by which work stressors may lead to CWB. 


\section{Work Stressor Hypotheses}

Organizational justice, interpersonal conflict, organizational constraints, and workload are the stressors relevant to the current study. These stressors were selected because previous research has suggested a link between these stressors and CWB (Greenberg, 1990; Lim, 2002; Fox et al., 2001; Hershcovis et al., 2007; Chen \& Spector, 1992). In addition, this selection of stressors seems to provide a representative sample of the types of stressors commonly experienced in the workplace. This study seeks to replicate previous findings suggesting a main effect between work stressors and CWB. Thus, it is hypothesized that these four work stressors will be positively associated with both forms of CWB. See Table 1 for a full list of hypotheses for the proposed study.

Hypothesis 1: Work stressors (interpersonal conflict, organizational constraints, organizational injustice, \& workload) will be positively related to measures of CWB: As self-reported work stressors increase, self-reported CWB-I and CWB-O will increase Additionally, previous research has suggested that the type of stressor (organizational vs. interpersonal) may influence the form of CWB one engages in (Fox et al., 2001; Hershcovis et al., 2007; Bruk-Lee \& Spector, 2006). Accordingly, it is hypothesized that interpersonal stressors will be more strongly related with CWB-I while organizational stressors will be more strongly related with CWB-O.

Hypothesis 2a: Measures of interpersonal conflict will be more strongly associated with self-reported CWB-I than CWB-O

Hypothesis 2b: Measures of organizational constraints, organizational injustice, and workload will be more strongly associated with self-reported CWB-O than CWB-I 


\section{Personality and CWB}

Though previous research has supported a link between work stressors and CWB, as well as the mechanisms by which stressors lead to CWB, individual differences in personality might influence one's tendency to engage in CWB. Because personality traits reflect peoples' characteristics and tendencies to act in certain ways (Tellegen, 1991), it seems possible that certain aspects of personality may play a role in a person's likelihood of engaging in CWB. In fact, personality has been repeatedly shown to be associated with CWB. Many different aspects of personality, including facets within the Five-Factor Model of personality as well as individual personality traits, have been suggested as having both main and moderating effects on the occurrence of CWB. Thus, certain personality traits may exacerbate or ameliorate the relationship between work stressors and CWB.

Five-Factor Model and CWB

The Five-Factor Model of personality, introduced by McCrae and Costa (1987), and also known as the Big Five, has received considerable attention regarding how personality may relate to CWB. Several studies have found evidence suggesting that dimensions of the Big Five are related to CWB (e.g. Salgado, 2002), and that certain dimensions of the Big Five may be differentially related to CWB-I and CWB-O (e.g. Mount et al., 2006). For example, Berry and colleagues (2007) theorize that agreeableness is more interpersonally oriented whereas conscientiousness is less so; therefore it makes logical sense that agreeableness would be more strongly associated with CWB-I while conscientiousness would be more strongly associated with CWB-O. Overall, the largest correlations among the Big Five dimensions have been found for conscientiousness, agreeableness, and neuroticism. Unlike agreeableness and conscientiousness, neuroticism does not seem to differ in predicting CWB-I and CWB-O; the less emotionally 
stable people are, the more likely they seem to engage in both forms of CWB (Rotundo \& Spector, 2010). Thus, the Big Five personality framework seems to be useful in predicting both forms of CWB.

Recently, there has been increased interest in examining the moderating effects of the Big Five dimensions. For example, Bowling and Eschleman (2010) examined conscientiousness, agreeableness, and negative affectivity as potential moderators in the work stressor-CWB relationship. It was found that workers who were low in conscientiousness or high in negative affectivity had stronger positive relationships between work stressors and CWB than workers who were high in conscientiousness or low in negative affectivity; agreeableness did not significantly moderate the relationship. However, Flaherty and Moss (2007) discovered in a previous study that both agreeableness and neuroticism served as moderators in the relationship between organizational justice and CWB. As other researchers have pointed out, organizational injustice can also be perceived and classified as a type of work stressor. Therefore, these studies provide evidence suggesting that work stressors and personality seem to have interactive effects on CWB.

Though the five-factor model provides a parsimonious model of personality, there are still aspects of personality that are not captured within the big five. Thus, individual traits outside of the five-factor model may also influence CWB. The trait of interest in the current study is work locus of control, and lies outside the realm of the big five, as no facets within the big five capture the element of control perceptions. Thus, it is expected that employee perceptions of control are likely to interact with work stressors in predicting CWB. Before explaining locus of control, two individual traits that have been shown to be related to CWB will be reviewed. 


\section{Individual Personality Traits and CWB}

In addition to dimensions of the Big Five, individual personality traits have also been suggested as having an association with peoples' tendency to engage in CWB. Trait anger and trait anxiety are personality dimensions that measure a person's likelihood of experiencing certain emotions; trait anger refers to the predisposition to experience situations as annoying, and trait anxiety, also known as negative affectivity, refers to the tendency to experience negative emotions across multiple situations (Rotundo \& Spector, 2010). Previous studies have demonstrated a link between trait anger and CWB, suggesting a positive relationship between the two variables (Fox et al., 2001; Spector \& Fox, 2002; Penney \& Spector, 2002). The same relationship has been found for negative affectivity, with higher levels associated with increased CWB (Fox \& Spector, 1999; Fox et al., 2001). Thus, people who have greater tendencies to experience situations as annoying (trait anger) and people with greater tendencies to experience negative emotions (negative affectivity) seem to be more likely to engage in CWB. This demonstrates the importance of personality measures that take into account an employee's tendency to experience certain emotions.

These traits have also been shown to have interactive effects with work stressors in predicting CWB. Penney and Spector (2005) found that negative affectivity moderated the relationship between three different work stressors (workplace incivility, interpersonal conflict, organizational constraints) and CWB; the relationship between each stressor and CWB was more strongly positive for people with high negative affectivity than for those with low negative affectivity. Similarly, Fox and colleagues (2001) found evidence in support of both trait anger and trait anxiety as moderators of the work stressor-CWB relationship. Specifically, it was found that for people with high levels of anger and anxiety, stressors were more strongly related to 
CWB. The authors suggest that people who tend to experience more negative emotions may be more sensitive and/or hyper-reactive to job stressors. This increased sensitivity to stressors may then result in increased behavioral reactions such as CWB; this provides further support for the notion that personality has the ability to impact the way a person responds to work stress.

As can be seen, previous research suggests that personality may be an important contributor to employee's engagement in CWB. Though the Big Five, as well as trait anger and anxiety, seem to contribute to CWB, there are other personality variables that should be considered when examining this topic: one of which is locus of control. Authors have recently stated the need for increased research into the influence of locus of control on CWB (i.e. (Spector \& Fox, 2002; Fox \& Spector, 2006). Accordingly, work locus of control is the personality trait relevant to the current study.

\section{Work Locus of Control}

Locus of control (LOC) refers to the extent to which people believe they can control events that affect them (Rotter, 1990). This is typically divided into internal and external LOC. People with high internal LOC (internals) believe that outcomes are the result of their own behavior and actions, whereas people with high external LOC (externals) believe that outcomes are due to chance, luck, or fate, are due to other people, or are unpredictable (Rotter, 1990). For example, when faced with a poor performance evaluation, internals are more likely to blame themselves, looking at their own behavior in order to see what they can do better to improve; externals, on the other hand, will be more likely to blame external factors such as other people or the situation they were put in, seeing the rating as outside of their control. Thus, internals see outcomes as a result of their own actions and potentially under their control; externals, on the 
other hand, see outcomes as results of factors that are external to themselves and beyond their control.

Locus of control has been shown to be an important construct in terms of individual and organizational outcomes, as previous research has demonstrated an association between LOC and health outcomes (Wallhagen, Strawbridge, Kaplan, \& Cohen, 1994), job satisfaction and job performance (Judge \& Bono, 2001), well being in general (DeNeve \& Cooper, 1998), and wellbeing at work (Spector et al., 2002). In general, previous research has found that an internal LOC tends to be associated with more positive actions/outcomes while an external LOC tends to be associated with negative outcomes. Locus of control has also been proposed as an important variable in the explanation of human behavior within organizations. Spector (1982) suggests that LOC is related to motivation, effort, performance, satisfaction, job perceptions, compliance with authority, and supervisor style. Accordingly, it is important to examine LOC as it relates to organizational behavior.

The present study focuses on the organizational behavior of CWB. Locus of control has been suggested as an important variable to consider regarding its relationship to CWB (Fox \& Spector, 2006). Work locus of control is the personality variable relevant to the present study, and is defined as the tendency to believe that one does or does not have control over work outcomes (Spector, 1988). Thus, whereas general LOC refers to the extent to which a person believes that rewards and life outcomes are (or are not) under one's own control, work LOC focuses specifically on the work domain. For example, work outcomes might include aspects such as promotions, salary increases, or job satisfaction. As with general LOC, people who believe they do have control over outcomes are referred to as internals, while those who do not 
believe they have control are referred to as externals. Control is a critical aspect of voluntary work behavior, including CWB.

Work LOC was selected for this study, as opposed to general LOC, because the proposed study was specifically focused on the work domain. Spector (1988) noted that the use of a general LOC measure with work-related variables has led to limited relationships. In addition, it has been advocated that researchers develop domain specific measures of the LOC construct (Spector, 1988). As previously mentioned, general LOC measures represent broad, allencompassing beliefs. The Work Locus of Control Scale, however, provides a measure that is specifically focused on employee beliefs about their control over work outcomes rather than outcomes in general. These can be two separate entities, as a person's domain specific LOC may differ from their overall general LOC. Therefore, because this study focused specifically on the work environment rather than other aspects of life, the domain specific Work Locus of Control Scale was used.

\section{Work Locus of Control and CWB}

In general, higher control over a situation tends to increase the likelihood of positive behavior and reduce the likelihood of negative behavior, while lower control tends to have opposite effects (Spector \& Fox, 2002). Though some studies have examined control in relation to CWB, researchers have noted that empirical support for the link between LOC and CWB is limited (Spector \& Fox, 2002; Fox \& Spector, 2006). A notable exception that has examined work LOC as it relates to CWB is Fox and Spector (1999). Among a sample of full time employees, Fox and Spector (1999) found that work LOC was positively associated with experienced frustration, and frustration was positively associated with CWB (i.e. work frustration-aggression model). The authors suggest that work LOC may impact the experience of 
frustration, as well as the behavioral responses to experienced frustration. Accordingly, it may be that employees who feel they lack control at work experience more frustration than employees who feel they have control. This increased frustration may serve as the means by which work LOC leads to CWB; engaging in CWB may allow the employees to release their frustrations.

Other researchers have also found an association between general LOC and CWB. For example, Heacox (1996) found that LOC was positively related to aggression against others, with externals showing more aggression. Additionally, among a sample of direct-care workers, Perlow and Latham (1993) discovered that people with an external LOC were more likely to physically abuse nursing home clients than people with an internal LOC. Thus, it seems that those with an external orientation are more likely to engage in CWB. These results provide further support for the importance of examining work LOC as it relates to CWB. Accordingly, it is hypothesized that work LOC is associated with CWB. Specifically, it is expected that an external locus of control will be positively related to both CWB-I and CWB-O.

Hypothesis 3: Higher scores on the Work Locus of Control Scale (external orientation) will be associated with an increase in self-reported CWB-I and CWB-O

\section{Work Locus of Control as a Moderator}

In addition to main effects, general LOC has also been examined as a moderator variable. In general, it seems that previous research supports the notion that externals have a greater tendency to experience and/or engage in negative outcomes in response to stress than internals (e.g. Perlow \& Latham, 1993; Fox \& Spector, 1999). People with an internal LOC tend to engage in more adaptive behaviors and experience greater psychological and physiological benefits than people with an external LOC (Wallhagen et al., 1994). For example, Sandler and Lakey (1982) found that LOC beliefs moderate the effects of stress on well-being: internals tend 
to experience less anxiety and depression in response to stress than externals. These authors suggested that under conditions of high stress, internals obtain and use information more effectively than externals and that internals are more task-oriented in their coping behaviors. This may be due to externals' feelings of helplessness; externally oriented people may feel like there is nothing they can do to change their situation. Hiroto (1974) found that people with an external LOC tend to demonstrate more helpless behavior than those with an internal LOC. Thus, applied to a working context, if employees feel they lack control over work outcomes, they may feel helpless in that they believe there is nothing they can do to change their situation. On the other hand, internals may take a more problem-focused approach in dealing with their problems in a more productive way.

Storms and Spector (1987) provided indirect support for the notion that externals tend to engage in more CWB in response to events in the work environment compared to internals. This study examined the role of work LOC as a moderator of the relationship between organizational frustration and CWB among employees within a mental health facility. The results showed little support for a direct link between work LOC and CWB; however, it was found that work LOC did significantly moderate the relationship between organizational frustration and CWB. Specifically, the relation between organizational frustration and CWB was more strongly positive for those with an external work LOC compared to those with an internal work LOC. An implication of this finding is that externals may be more likely to engage in CWB in response to frustration than internals. The results from this study are expected to be replicated in the current study. Thus, it is hypothesized that work LOC will moderate the relationship between frustration and CWB. It is expected that higher levels of frustration will be positively associated with both forms of CWB, and that this effect will be greater for those with an external work LOC. 
Hypothesis 4: Work locus of control will moderate the relationship between organizational frustration and CWB: organizational frustration will have a greater influence on CWB for those with higher scores on the Work Locus of Control scale (externals) than those with low scores (internals)

A possible explanation for the link between work LOC and CWB is that people with an external work LOC may attempt to change their environment and increase feelings of control by engaging in destructive acts (Allen \& Greenberger, 1980). In this case, after experiencing frustration, employees with an external work LOC may act out in the form of CWB in order to exert control over their environment; these destructive acts may help the employee to avoid feelings of helplessness. Conversely, internals may find more productive ways of dealing with their frustration, such as talking with a supervisor or coworker. Thus, CWB may serve as a way for externally oriented employees to increase their perceptions of control over their work environment.

Storms and Spector's study is relevant to the present study because it was the only study found examining work LOC as a moderator variable in predicting CWB; thus, its findings have yet to be replicated. Additionally, the present study examines a broad sample of work stressors rather than overall frustration. Work LOC has not yet been examined as a moderator of the relationship between work stressors and CWB. Other studies that have viewed forms of control as a moderator have found inconsistent results. For example, Fox and colleagues (2001) hypothesized perceived autonomy, a form of job control, as a moderator between job stressors and CWB. Autonomy was defined as perceived control over work tasks. It was expected that people who perceived low autonomy would be more likely to respond to job stressors with 
CWB. The results indicated no support for the hypothesized moderating role of autonomy in the stressor-CWB relationship. However, the authors noted that autonomy may represent a taskrelated measure and may be too specific of a measure to pair with the broad domain of CWB (Fox et al., 2001). The present study focuses on work LOC, which represents a broader measure of control assessing beliefs about work in general. Therefore, this measure should be more useful in predicting the different forms of CWB.

Given the results of previous LOC and CWB research, it is reasonable to expect that work LOC may play a significant role in the relationship between work stressors and CWB. As mentioned previously, research has demonstrated that internally oriented people tend to deal with outcomes in more adaptive, task-oriented ways because they feel that they can change their current situation. Externals, on the other hand, tend to feel like there is nothing they can do to change their outcomes, and this perception of lack of control can lead to feelings of helplessness. As a result, externals may engage in any action that may help them gain a sense of control, such as CWB. Thus, it is hypothesized that work LOC will moderate the relationship between work stressors and CWB (see Figure 1). It is expected that higher levels of work stressors will be associated with an increase in both forms of CWB, and that this effect will be greater for those with an external work LOC.

Hypothesis 5: Work locus of control will moderate the relationships between work stressors and CWB: Work stressors will be more strongly and positively related to CWB for those with higher scores on the Work Locus of Control scale (externals), compared to those with low scores (internals) 


\section{CHAPTER 2. METHOD}

\section{Participants}

Participants in the present study were recruited from a pool of full-time U.S. workers provided by the StudyResponse Project (SRP; Stanton \& Weiss, 2002). The SRP consists of a database containing over 80,000 people who have agreed to participate in online research. A total of 480 potential participants were recruited through email and provided with links to the study survey. Of these, 208 completed surveys and were used for data analysis (43\% response rate). The mean participant age was 39.24 years $(\mathrm{SD}=10.38)$ with an average job tenure of 8.5 years $(\mathrm{SD}=6.3)$. Just over half of the participants were male $(53.6 \%)$, and most were Caucasian (76.9\%). A variety of occupations were represented in this sample, including manufacturing, health care, education, retail, finance, and telecommunications.

\section{Procedure}

Emails were sent to potential respondents through the StudyResponse website explaining general details regarding the topic of study; a link was included on the email so that interested recruits could proceed to the study website. An approximate 20 minute questionnaire containing study variables and demographic information was posted as an online survey. Prior to completing the survey, participants were asked to read and agree to informed consent. Participants were then asked to complete the online survey. The identity of the participants remained anonymous, as they only entered their StudyResponse ID as an identifier; this ID only provided demographic information and in no way allowed personal identification of the participants. After submitting the completed survey, participants were administered a $\$ 5$ gift card to an online retailer as an incentive for participation. This incentive was administered through the StudyResponse website. 
Measures

Organizational Constraints. Organizational constraints were measured using the Organizational Constraints Scale ( $\alpha=.93$; Spector and Jex, 1998). This scale consists of 11 items assessing aspects of the job that prevent employees from translating ability and effort into high levels of job performance. Each item presents a job-relevant aspect/situation: examples of the items include "poor equipment or supplies" and "conflicting job demands." For each item, the participant was asked to indicate how often it is difficult or impossible to do his/her job because of the aspect presented. Response choices range from 1 (less than once per month or never) to 5 (several times per day). High scores represent high levels of constraints.

Interpersonal Conflict. Interpersonal conflict was measured using the Interpersonal Conflict at Work Scale ( $\alpha=.94$; Spector and Jex, 1998). This scale consists of four items assessing how well an employee gets along with others at work. An example item is, "How often do you get into arguments with others at work?" For each item, participants were asked how often this occurs at work; responses range from 1 (rarely) to 5 (very often). High scores represent more frequent conflict with others.

Workload. Workload was measured using the Quantitative Workload Inventory $(\alpha=.89$; Spector and Jex, 1998). This scale consists of five items assessing the amount of work the participant must perform. Each item represents a statement about the participant's amount of work, and participants were asked to indicate how often each occurs; responses to each item range from 1 (less than once per month or never) to 5 (several times per day). An example of an item is, "How often does your job leave you with little time to get things done?" High scores represent a high level of workload. 
Organizational Justice. Organizational justice $(\alpha=.96)$ was assessed similar to Fox et al. (2001). Perceptions of organizational justice were measured by combining the distributive and procedural justice scales reported in Moorman (1991). Six items from the Distributive Justice Index, developed by Price and Mueller (1986), were used to measure the extent to which an employee is fairly rewarded for work inputs: responsibilities, experience, effort, performance, and job stress. Responses were on a 5 point scale, ranging from 1 (very unfairly) to 5 (very fairly); a high score represents a high level of distributive justice. Procedural justice was assessed with a 12 item procedural justice scale developed by Moorman (1991); this scale was based on Levanthal's rules of procedural justice. Responses on this scale range from 1 (strongly disagree) to 5 (strongly agree) with high scores representing high levels of procedural justice. The distributive and procedural justice scales were combined to produce an overall measure of justice. Lower scores represent perceived injustice.

Work Locus of Control. Work LOC $(\alpha=.72)$ was measured using the short form of Spector's Work Locus of Control Scale (Spector 1988). This scale consists of 8 items assessing employee beliefs about their control at work in general. Half the items reflect an external LOC and half reflect an internal LOC. An example of an external LOC item is, "Getting the job you want is mostly a matter of luck." An example of an internal LOC item is, "People who perform their jobs well generally get rewarded." Each item consists of six response choices ranging from 1 (disagree very much) to 6 (agree very much). High scores represent externality and low scores represent internality.

Frustration. Frustration $(\alpha=.64)$ was measured using the 3 item scale developed by Peters, O'Connor, and Rudolf (1980). This scale measures perceived frustration on a six point 
scale ranging from 1 (strongly disagree) to 6 (strongly agree). High scores represent high levels of frustration. An example of an item from this scale is "being frustrated comes with the job." Counterproductive Work Behavior. Counterproductive work behavior was measured using the 33 item Counterproductive Work Behavior Checklist $(\alpha=.99$; Spector et al., 2006). This measure provides a composite CWB score which can be broken down into behaviors targeting the organization (e.g. "told people outside the job what a lousy place you work for") or behaviors targeting other people within the organization (e.g. "made fun of someone's personal life"). Each item consists of five response choices ranging from 1 (never) to 5 (every day). Due to the high correlation between the two dimensions $(r=.95)$, aggregate measures were used for the majority of analyses. High scores represent higher levels of counterproductive behavior.

Controls. Age, sex, and job tenure were controlled for in all analyses in order to prevent confounding of the relationship between stressors and CWB. Previous research has suggested that older people, females, and employees with more tenure tend to engage in less CWB (Rotundo \& Spector, 2010). As such, controlling for these factors will ensure that they are not a driving factor of the relationships between work stressors, work LOC, and CWB.

Negative affectivity has also been shown to have an effect on the relationship between stressors and CWB, with employees high in negative affectivity demonstrating a stronger relationship between stressors and CWB than those with low negative affectivity (Penney \& Spector, 2005). In order to account for this possibility, negative affectivity was controlled for in all analyses. Trait negative affectivity $(\alpha=.95)$ was assessed with the negative affect dimension of the Positive and Negative Affect Schedule (PANAS) developed by Watson, Clark, and Tellegen (1988). This scale contains 10 items assessing the extent to which a person experiences distress and aversive mood states. Participants were asked to rate the extent to which they feel a 
certain way in general, as operationalized by adjectives describing feelings and emotions: response choices range from 1 (very slightly or not at all) to 5 (extremely). Items include feelings such as "hostile" and "irritable." High scores represent high negative affectivity.

For the interaction hypotheses, general LOC was also controlled for in order to specifically examine work LOC as a moderator variable. General LOC $(\alpha=.85)$ was measured with a 9-item scale developed by Sapp and Harrod (1993). This scale was developed as a brief version of Levenson's (1973) 24-item locus of control scale. Examples of items from this scale include "my life is determined by my own actions" and "my life is chiefly controlled by powerful others." Participants were asked to respond on a scale ranging from 1 (strongly disagree) to 6 (strongly agree). Higher scores represent externality and low scores represent internality.

\section{Method of Analysis}

Hierarchical regression was used to test the main effect hypotheses. Control variables (age, sex, tenure, negative affectivity) were entered into the first step of the analyses, and predictor variables were entered into the second step of the analysis, with CWB as the dependent variable. A dominance analysis was used to test hypothesis 2 . This procedure provides an estimate of the relative importance of each predictor based on a subset of all possible regression models (LeBreton \& Tonidandel, 2008). It produces dominance weights that can be compared in order to determine which predictor has a larger impact on the dependent variable while controlling for multicollinearity. As a result, the predictors can be rank-ordered in terms of importance regarding the criterion of interest - in this case, CWB-I and CWB-O.

To test the interaction hypotheses, the three-step procedure described by Baron and Kenney (1986) was used. In the first step, control variables (age, sex, tenure, negative 
affectivity, general locus of control) were entered. In the second step, the predictor and the moderator variable were entered in the equation. In the final step, an interaction term, computed by multiplying the centered scores for the predictor and moderator variables, was entered into the equation. In order to determine if there was a significant moderation effect, the change in $R^{2}$ from step 2 to step 3 was examined. Variables were centered for all analyses, as mean centering has been advocated as aiding in the interpretation of results (Aiken \& West, 1991). 


\section{CHAPTER 3. RESULTS}

Due to the data collection method, it is possible that results may be influenced by common-method bias, as all measures were self-reported at the same point in time. Harmon's one-factor test was conducted in order to test for the presence of common method effects (Podsakoff, MacKenzie, Lee, \& Podsakoff, 2003). The results of the test revealed multiple factors with eigenvalues of greater than 1.0, rather than a single factor. As such, the majority of the variance in the measures cannot be accounted for by a single factor; thus, no general factor seems to be present.

Table 2 displays descriptive statistics and coefficient alphas for all study variables. The mean and standard deviation of CWB is similar to that of previous CWB research (e.g. Penney \& Spector, 2005; Bowling \& Eschleman, 2010). Based on the observed ranges of the self-reported variables found in Table 2, it seems that range restriction was not a problem. Intercorrelations among the variables can be found in Table 3; the majority of correlation coefficients were in the expected direction. Although it was expected that the two dimensions of CWB would be significantly related, the unusually high correlation $(\mathrm{r}=.95)$ between CWB-I and CWB-O was unexpected. A principle components analysis of the CWB items also failed to produce two factors, with all items loading onto one general factor. Due to the magnitude of this correlation, aggregate measures of CWB were used for the majority of the analyses rather than testing CWBI and CWB-O separately. Because hypothesis 2 expected differences in the prediction of CWB-I and CWB-O, this was the only analysis that distinguished between the two CWB dimensions.

Regarding correlations between the independent variables and the dependent variable, CWB was significantly related to organizational constraints $(\mathrm{r}=.65)$, interpersonal conflict $(\mathrm{r}=$ $.84)$, workload $(\mathrm{r}=.19)$, work LOC $(\mathrm{r}=.37)$, and organizational frustration $(\mathrm{r}=.27)$. This 
provides initial support for the majority of the hypotheses. Organizational justice, however, was not significantly related to CWB. Additionally, four of the five control variables (age, sex, negative affectivity, general LOC) were significantly correlated with CWB in the expected direction; job tenure was not significantly related to CWB.

\section{Main Effect Hypotheses}

Hypothesis 1 examined the relationship between four work stressors and CWB. It was hypothesized that work stressors would be positively related to CWB. After controlling for age, sex, job tenure, and negative affectivity, three of the four work stressors were significantly related to CWB. Specifically, organizational constraints $(b=.47, p<.05)$ and interpersonal conflict $(b=.70, p<.05)$ were found to significantly predict CWB in the hypothesized direction. Organizational justice also demonstrated a significant relationship with CWB $(b=.14, p<.05)$; however, the direction of this relationship was contrary to the hypothesis. It was expected organizational injustice (low levels of justice) would be associated with increased CWB; these results, however, found a positive association between organizational justice and CWB. Workload was not a significant predictor of CWB $(b=.11, p=.053)$. This provides partial support for hypothesis 1.

Hypothesis 2 proposed that interpersonal conflict would be a stronger predictor of CWB-I while organizational constraints, workload, and organizational justice would be stronger predictors of CWB-O. To further examine the significant relationships found in hypothesis 1 , a dominance analysis was performed. Because workload was not a significant predictor, it was excluded from the analysis. Results from the dominance analysis indicate that interpersonal conflict proved to be the strongest predictor (general dominance index $=.26$ ) of CWB-I, followed by organizational constraints (general dominance index $=.06$ ) and organizational 
justice (general dominance index $=.05$ ). Similar results were found for CWB-O: interpersonal conflict was the most dominant predictor (general dominance index $=.23$ ), again followed by organizational constraints (general dominance index $=.06$ ) and organizational justice (general dominance index $=.04$ ). This provides partial support for hypothesis 2 , as interpersonal conflict was the strongest predictor for CWB-I. However, contrary to expectations, interpersonal conflict was also the strongest predictor of CWB-O. These results suggest that interpersonal conflict accounts for the most variance in overall CWB. Additionally, this result could be due to construct overlap between interpersonal conflict and CWB; the high correlation between the two suggests that participants may have had trouble distinguishing the two constructs.

Hypothesis 3 investigated the relationship between WLOC and CWB. It was expected that higher scores on the Work LOC Scale would be positively associated with CWB, as higher work LOC scores indicate an external orientation. Results of the regression indicate that work LOC is predictive of CWB above and beyond the control variables in the hypothesized direction $(b=.21, p<.05)$. Thus, to the extent that a person has an external work LOC, they seem to be more likely to engage in CWB, fully supporting hypothesis 3.

\section{Moderation Hypotheses}

Hypothesis 4 sought to replicate a previous finding by Storms and Spector (1987). Specifically, it was expected that work LOC would moderate the relationship between organizational frustration and CWB. Table 4 provides the results of the three-step hierarchical regression analysis. Because the interaction term did not reach significance $(b=.05, p>.05)$, the results failed to provide statistical support for the moderating effect of work LOC in the relationship between organizational frustration and CWB. Therefore, hypothesis 4 was not supported. 
Hypothesis 5 proposed that work LOC would moderate the relationship between four work stressors and CWB. Results from the organizational constraints analysis are displayed in Table 5. The significant interaction term $(b=.29, p<.05)$ of work LOC and organizational constraints explained an additional $2 \%$ of the variance in predicting CWB above and beyond the control, independent, and moderator variables. The form of this interaction was graphed in Figure 2, suggesting that the relationship between organizational constraints and CWB is more strongly positive for externally oriented employees compared to those who are internally oriented. A simple slopes analysis (Aiken \& West, 1991) provided further support, indicating that the high work LOC slope $(+1 S D)$ was significant $(b=.59, \mathrm{t}(196)=6.79, p<.05)$ while the low work LOC slope $(-1 S D)$ was not $(b=.16, \mathrm{t}(196)=1.48, p>.05)$.

Interpersonal conflict was tested next; table 6 displays the results from this analysis. The significant interaction term in step 3 of the analysis $(b=.25, p<.05)$ accounted for an additional $1 \%$ of the variance in $\mathrm{CWB}$, indicating that work LOC is a significant moderator in the relationship between interpersonal conflict and CWB. This interaction is graphed in Figure 3, showing that the relationship between interpersonal conflict and CWB is more strongly positive for externals than for internals. Simple slopes analysis supported this, indicating that when work LOC was high (external), employees tend to engage in more CWB as a result of interpersonal conflict $(b=.76, \mathrm{t}(196)=13.88, p<.05)$ than when work LOC was low $(b=.39, \mathrm{t}(196)=3.71$, $p<.05)$

Regarding workload, there was no significant interaction between workload and work LOC in predicting CWB $(b=.11, p>.05)$. Results for this analysis can be found in Table 7. Finally, Table 8 displays results from the organizational justice. The significant interaction term $(b=.15, p<.05)$ between organizational justice and work LOC predicts an additional $2 \%$ of the 
variance in CWB above and beyond step 1 and 2. Figure 4 displays this interaction, showing that the relationship between organizational justice and CWB was more strongly positive for externals compared to internals. This is contrary to the hypothesis, as it was expected that employees with lower levels of justice would be more likely to engage in CWB than those who experience higher levels of justice. Simple slopes analysis provided further support, showing that the high work LOC slope was significant $(b=.29, \mathrm{t}(196)=4.44, p<.05)$ while the low work LOC slope was not significant $(b=.06, \mathrm{t}(196)=0.84, p>.05)$. The combined results of the four moderator analyses provide partial support for hypothesis 5; organizational constraints and interpersonal conflict interacted with work LOC as expected, organizational justice displayed a significant interaction but in an unexpected direction, and workload did not significantly interact with work LOC.

Because general LOC has a rather strong correlation with CWB $(\mathrm{r}=.52)$, it is possible that the results of the interaction analyses for work LOC may be stronger if the variance accounted for by general LOC is not controlled for. Thus, post-hoc analyses were conducted for all the moderation hypotheses excluding general LOC as a control variable in order to determine if this would have an impact on the present findings. Results from these analyses indicate that the beta weights for the interaction terms were comparable for all hypotheses in which general LOC was a control variable, and no significant changes resulted due to the removal of general LOC. 


\section{CHAPTER 4. DISCUSSION}

The primary purpose of the current study was to investigate the moderating role of work LOC in the relationship between four work stressors and CWB. Although previous research has demonstrated a positive relationship between various work stressors and $\mathrm{CWB}$, as well as several personality traits that may influence these relationships, this is one of the first to examine work LOC in relation to CWB. Researchers have recently suggested that there is insufficient knowledge on the link between LOC and CWB and have called for increased research on the topic (Spector \& Fox, 2002; Fox \& Spector, 2006). This study addresses this issue by examining the role of work LOC in the work stressor-CWB relationship. The present study helps to further explain why certain employees tend to react to work stressors by engaging in CWB. Results suggest work LOC may play an important role in the work stressor-CWB relationship.

\section{Main Effects}

The results partially supported the assertion that work stressors are positively associated with CWB. Regarding the main effects of this study, it was found that organizational constraints, interpersonal conflict, and organizational justice were predictive of CWB, while workload was not. Additionally, work LOC was significantly related to CWB. These effects will be discussed in turn.

Organizational constraints and interpersonal conflict were both positively associated with CWB. Specifically, employees who perceived greater levels of organizational constraints and/or interpersonal conflict also reported engaging in more CWBs. These findings are in line with previous CWB research (Fox et al., 2001; Bowling \& Eschleman, 2010; Rotundo \& Spector, 2010). Thus, as discussed in the introduction, employee engagement in CWB may be the result of negative emotional reactions stemming from the experience of these two work stressors 
(Weiss \& Cropanzano, 1996; Fox \& Spector, 2006). Additionally, CWB may also simply represent a response to ineffective coping with stressors (Cullen \& Sackett, 2003). Thus, employees may engage in CWB in response to work stress because they may lack the ability, or awareness, to access alternative coping strategies. Overall, converging with prior research, the results suggest organizational constraints and interpersonal conflict as significant predictors of CWB.

One potential problem, however, is the unusually high correlation between interpersonal conflict and CWB $(\mathrm{r}=.84)$. This correlation is much higher than previous studies examining these two variables (e.g. Fox et al., 2001; Penney \& Spector, 2005; Chen \& Spector, 1992). Bowling and Eschleman (2010) used the same sampling method as the current study (StudyResponse), reporting rather high correlations between interpersonal conflict and the interpersonal $(r=.66)$ and organizational $(r=.58)$ dimensions of CWB, but not to the extent of the present study. Though it is easy to distinguish between interpersonal conflict and CWB conceptually (i.e. conflict does not necessarily imply intent to harm), this may be a difficult distinction for survey respondents to make. Thus, it is possible that respondents in this study may have failed to distinguish the two concepts when filling out the survey. However, a principal components analysis did find two factors, with interpersonal conflict items and CWB items differentially loading onto the appropriate factors. This suggests that the items were measuring two distinct, but highly related constructs. Regardless, it is important to acknowledge the high correlation between the two variables as it may impact the results of the study.

It was also found that the main effect of organizational justice on CWB was opposite of the direction hypothesized, as it was expected that perceived injustice would be associated with higher levels of CWB. Results suggest that as employees perceptions of justice increase, so does 
their self-reported CWB. In other words, to the extent that employees perceived that they were being treated fairly (as opposed to unfairly), they tended to engage in more CWB. This result is counterintuitive and clearly diverges from previous research examining organizational justice in relation to CWB (Fox et al., 2001; Skarlicki \& Folger, 1997). Prior studies support the idea that situations seen by employees as unfair may lead to lower perceptions of justice and negative emotions, and subsequently counterproductive actions against the organization. The present study contradicts these explanations.

One possible explanation for this is that CWB may be driving perceptions of justice. In other words, engaging in CWB may influence employees' perceptions of justice; employees engaging in destructive acts against the organization may feel that these actions increase justice, or restore/repair justice, between themselves and the organization they are working for. Another possibility is that employees may believe they are being treated fairly, but may not believe the organization's intentions are genuine. Accordingly, employees may feel that the organization is doing just enough to get by and is possibly worried more about presentation than actual employee well-being.

The remaining work stressor, workload, was not significantly related to CWB. This diverges from previous findings that have found a significant relationship between the two variables (e.g. Chen \& Spector, 1992; Bayram, Gursakal, \& Bilgel, 2009), but is not as surprising as the result for organizational justice. The lack of a significant result may be due to the fact that this study investigated overall CWB, rather than separating CWB into separate dimensions. Bayram et al. (2009) found that workload was a significant predictor only for the abuse and withdrawal dimensions of CWB. Additionally, although workload was concluded to be positively related to CWB in Bayram and colleagues study, the authors noted that the 
relationship between workload and CWB tends to be weak and less important than other aspects of the work environment such as constraints, conflict, and job satisfaction. Furthermore, Galperin and Burke (2006) found that workaholics who were highly involved in their jobs and felt driven to achieve high performance tended to engage in less CWB. Thus, it seems that factors other than workload seem to be more important in predicting CWB and that workload, by itself, may not be a sufficient predictor of CWB.

Work LOC was the variable of interest in the current study and was found to significantly predict CWB. Specifically, higher scores on the work LOC scale (external orientation) were associated with increased CWB. In other words, to the extent that employees feel a lack of control over their work situation, the more likely it seems that they will engage in CWB. This is in line with previous findings regarding general LOC (Perlow \& Latham, 1993; Heacox, 1996) and work LOC (Fox \& Spector, 1999) as they relate to CWB. This result also provides support for Wallhagen and colleagues' (1994) assertion that externals tend to engage in less adaptive behaviors than internals. Additionally, it may be that some employees engage in destructive acts (such as CWB) in an attempt to feel some sort of control over their situation (Allen \& Greenberger, 1980) and to potentially avoid feelings of helplessness (Hiroto, 1974). Thus, the significant relation between work LOC and CWB suggests work LOC as an important variable and a potential moderator of the relation between work stressors and CWB.

\section{Interactive Effects of Work Stressors and Work LOC}

The most important contribution of the current study involves the examination of a novel moderator (work LOC) of the work stressor-CWB relationship. These findings extend previous research by examining work stressor-personality interactions that had been left unexamined by prior studies (e.g. Penney \& Spector, 2005; Bowling \& Eschleman, 2010). It was found that 
work LOC significantly interacted with organizational constraints, interpersonal conflict, and organizational justice in predicting CWB. Workload, however, did not display a significant interaction with work LOC. These effects will be discussed in turn.

Regarding organizational constraints and interpersonal conflict, the interactions with work LOC were significant and consistent with the hypotheses. Specifically, it was found that organizational constraints and interpersonal conflict yielded stronger positive relationships with CWB among workers with an external work LOC compared to workers with an internal work LOC. This finding may reflect the fact that employees with an external orientation may feel they lack better options because they have little control over their work situation. Thus, CWB may represent an ineffective coping strategy (Cullen \& Sackett, 2003). Those with an internal work LOC, in contrast, may find other more constructive coping strategies before resorting to CWB. It's possible that external's are more likely to engage in CWB in order to gain some sort of control over their situation (Allen \& Greenberger, 1980), while internals are less likely because they perceive more control and the possibility of better options for dealing with work stress. For example, internals may try actions such as talking with a supervisor or coworker to resolve the issue before engaging in CWB. This is along the lines of Hiroto's (1974) assertion that externally oriented people are more likely to experience feelings of helplessness. Another possible explanation is that employee personality traits may influence an employee's threshold for engaging in CWB (Bowling \& Eschleman, 2010). Specifically, those with an external work LOC may engage in CWB in response to any work stressor, regardless of how severe. Internals, on the other hand, may engage in CWB only in response to extreme levels of work stressors because they have a higher threshold for engaging in CWB. 
The interaction between organizational justice and work LOC was not so straight forward, displaying some interesting results. Though work LOC did significantly moderate the relationship between work stressors and CWB, with externals having a stronger relationship than internals, the form of the interaction was contrary to our hypothesis. Results displayed that for externals, justice - not injustice - was positively associated with CWB. Similar to the main effect found for organizational justice, the result that increases in justice are associated with increased CWB is counterintuitive and diverges from previous research. A possible explanation for this unexpected result is that externals may expect injustice due to their perceived lack of control; when injustice is expected by employees, it may be less likely to lead to CWB. Similarly, if injustice is expected, these employees may not believe the intentions of the organization to be genuine even when the organization displays actions of justice and fairness. Thus, although external employees may perceive to be getting treated fairly by the organization, they may not truly believe the intentions of the organization are in the right place. Finally, because this is a cross sectional study, it may be that CWB is driving perceptions of justice. Because externals tend to engage in more CWB, they may perceive a greater amount of fairness because they see CWB as something that contributes to justice. Thus, CWB may serve as a way for employees to restore/raise perceptions of justice.

Regarding workload, work LOC did not serve as a moderator. Thus, no main or moderating effects were found with regard to workload. This result is a little more surprising than the lack of a main effect. In theory, it seems like employees with a combination of a large workload and little perceived control may be more likely to lash out against the organization. However, the results suggest that there is no interaction between work LOC and workload in predicting CWB. As such, other factors may be more important in the prediction of CWB. 
The present study extends the results of Fox and Spector's (1999) study, which found main effects of work LOC on CWB. This is one of the first studies to examine the interactive effects of work LOC in relation to CWB. Additionally, because the results did not replicate the interaction between frustration and work LOC in predicting CWB (Storms and Spector, 1987), results indicate that the emotion of frustration, in itself, may not be enough to predict CWB. This study provides more robust findings, suggesting that multiple stressors in the work environment may interact with work LOC to predict CWB.

Overall, this study is unique in that evidence was found for work LOC as having main and moderating effects above and beyond general LOC. Because significant effects were found even after controlling for general LOC, this study distinguishes work LOC as a distinct and robust construct as well as an important variable to consider in CWB research. Specifically, employees with an external work LOC seem to be more likely than those with an internal work LOC to engage in CWB in response to certain work stressors. Results provide support for Spector's (1998) model of job stress, which suggests that perceptions of control have both direct and moderating effects on the job stress process, and influences how the work environment is perceived. Findings from the current study suggest work LOC as a valuable personality trait and an important factor in the prediction of CWB.

\section{Practical Implications}

The findings from the current study have important implications for organizations and their policies. First of all, this study replicates the finding that certain work stressors are positively associated with CWB. As a result, organizations should be aware of the work stressors that may contribute to CWB and to the extent that they can, try to reduce these work stressors in the workplace. 
Regarding work LOC, findings suggest that organizations should be particularly concerned about work stressors leading to CWB among employees with an external work LOC. Given that work LOC demonstrated a main effect on CWB, as well as an interaction effect after controlling for general LOC, work LOC is an important trait to consider in the workplace with regard to CWB. Thus, organizations could target employees with an external orientation for stress interventions, teaching them how to more productively cope with stressors. Additionally, organizations might implement interventions to try to increase worker perceptions of work LOC. If employees feel like they have more control over their work setting, it is possible that they will engage in more productive actions when faced with work stressors (Cullen \& Sackett, 2003). Given that work LOC is specific to the work domain, it is unlikely that organizations can use results of the current study for improvement in selection. It may be possible to consider a measure of work LOC from previous jobs in the selection process; however, depending on the similarity of the previous job and the job the employee applies for, work LOC may or may not be an accurate indication of their expected work LOC on the prospective job. Unlike general LOC, work LOC may change due to a differing work environment.

The findings for organizational justice, although counterintuitive, suggest that it may be beneficial for organizations to "look the other way" when employees engage in some mild forms of CWB because this might be a way that employees restore equity. In fact, some studies have found that engaging in non-work activities while at work may be beneficial. For example, it has been suggested that allowing employees to use the internet for non-work tasks (i.e. cyberloafing) can actually be beneficial in that it allows employees to briefly escape from demanding job requirements (Verton, 2000). These online recreational activities can be constructive, as they may provide intellectual and psychological stimulation for the employee, which then helps the 
employee subsequently face tough challenges in the workplace with increased energy (Oravec, 2002). Thus, if employers allow employees to engage in minor forms of CWB, such as cyberloafing, it may enhance perceptions of justice, morale, and potentially productivity. Obviously, though, this would only apply to milder forms of CWB.

The results for justice may also highlight not only the importance of justice, but organizational intentions. The results suggest that even when employees perceive to be treated with justice, they still might engage in CWB. This may be due to employee perceptions of whether or not the organization is "genuine" in their treatment of employees. In other words, employees may not just look to be treated fairly, but also want the organization to truly care about the employees, not just justice for justice's sake. As such, organizations could not only work on improving organizational justice, but also the way in which justice is administered to employees. Similarly, organizations could seek employee input as to how to increase organizational justice perceptions by asking the employees what they want from the organization. These strategies may improve employee perceptions as to whether or not organizational intentions are truly genuine.

\section{Study Limitations}

Although the current study advances the literature on CWB by including a rather new personality variable (work LOC), it is not without limitations. First of all, this study relies solely on the use of self-report measures. As a result, results may have been influenced by commonmethod variance. Though some authors have recently argued that the problem of commonmethod variance is overstated (Spector, 2006), it is still a potential problem, especially when dealing with CWB. Deviance-related measures, like CWB, seem to be especially prone to socially desirable responding as employees may not want to reveal the extent to which they 
engage in deviant behavior in the workplace (Fox, Spector, Goh, \& Bruursema, 2007). As such, correlations between variables may be inflated due to socially desirable responding. However, self-report CWB may be more accurate than alternative measures because CWB are often performed outside the awareness of co-workers and supervisors (Spector \& Fox, 2005). Additionally, the detection of interactions in this study attenuates the problem of commonmethod variance, as one effect of common-method variance is decreasing the sensitivity of tests of moderators (Evans, 1985).

Another limitation of this study is the cross-sectional design. Because all data were collected concurrently, this does not allow for any causal conclusions to be made. Thus, although it was assumed that work stressors and work LOC influenced CWB, the results only show that these variables were related. It is also possible that CWB may be influencing employee work LOC and/or perceived work stressors. This makes it especially difficult to interpret the relation between work LOC and organizational justice. As such, longitudinal studies must be conducted in order to determine the causal relationship between work stressors, work LOC, and CWB.

The use of StudyResponse represents another potential limitation, as use of this voluntary method could have introduced a self-selection bias. It may be possible that the current sample is in some way different from the larger organizational workforce. For example, it is possible that those who accessed the online survey may be more or less satisfied with their organization and therefore may be more likely to agree to opportunities to share their feelings about their work situation. However, the use of this method of data collection rather than recruiting employees from a single organization is beneficial when assessing CWB, as StudyResponse ensures participant anonymity. This anonymity is crucial when asking participants about CWB (Fox et al., 2007). For example, employees recruited through a single organization may be less likely to 
supply honest answers for fear of having their employers or co-workers gaining access to their responses.

The study response sampling method also produces a sample consisting of a wide variety of occupations. Though this is beneficial in that it allows a sample of various workers in differing contexts, it is also a potential limitation. Due to the wide array of occupations, it is quite possible that some respondents may have had different opportunities to engage in CWB compared to others. For example, respondents with jobs in which they are relatively isolated from others, such as jobs that require employees to work on a computer all day, may not have many opportunities to engage in interpersonal forms of CWB, but have increased opportunity to engage in organizational forms of CWB, such as cyberloafing. Similarly, employees in the retail or restaurant industries may have more opportunities for theft than in other occupations. It is important to note that the types of CWB reported, as well as the prevalence of CWB, may vary according to occupations as some working contexts may be more conducive to engaging in CWB. Thus, in future research involving CWB, it may be useful to control for the characteristics of one's occupation.

\section{Future Directions}

Because this is one of the first studies examining the personality variable work LOC in relation to $\mathrm{CWB}$, there are many directions for future research. First of all, the majority of CWB research has been conducted using a cross-sectional design. In the workplace, employee attitudes, perceptions, and behaviors are likely to evolve due to daily events at work and history with their employers (Rotundo \& Spector, 2010). As such, it is encouraged that future research use longitudinal designs in order to measure these changes and determine the causal relationships between work stressors, personality, and CWB. 
Another direction for future research is to examine how personality may impact employee engagement in more productive forms of coping in response to work stressors. Thus, certain employees may tend engage in more problem-focused coping in order to reduce or eliminate the stressor, rather than engaging in CWB. For example, Carver, Scheier, and Weintraub (1989) outline various ways in which people can constructively cope with stress. These include actions such as actively working to get rid of the problem, planning ahead for potentially similar stressful situations, restraining oneself from acting too quickly/impulsively in response to a stressor, seeking social support, reappraising the situation, or mentally disengaging from the stressor by thinking or engaging in other activities. These strategies represent an alternative to immediately engaging in CWB in response to stress. Similarly, Bowling and Eschleman (2010) have suggested that personality may influence the extent to which employees engage in other responses prior to engaging in CWB. Thus, these authors are suggesting that certain employees may only engage in CWB in response to work stress after more constructive reactions proved ineffective, while other employees use CWB as their initial response. This is an interesting area for future investigation and would be beneficial for potential organizational policies and interventions.

Regarding the specific results from the current study concerning work LOC, the findings and conclusions should be considered preliminary, as this is one of the first studies to examine this personality variable in relation to work stressors and CWB. Future research should seek to replicate the current findings to gain a more complete understanding of work LOC's role in the prediction of CWB. Similarly, given the results found for organizational justice, future studies should seek to investigate whether this result can be replicated. Because findings regarding organizational justice were so different from previous studies, the results may be a characteristic 
of the specific sample collected. However, if the results are replicated, effort should be put forth to examine potential mediating mechanisms for why greater levels of justice could lead to increased CWB.

Finally, core self-evaluations (CSE) have emerged as an important variable to consider in behavioral research (Judge, Erez, Bono, \& Thoresen, 2003). Given that two components of CSEs - negative affectivity and locus of control - have been shown to be associated with CWB, it is possible that CSE's will be related to CWB. Future research on work LOC may even control for CSE in order to examine whether work LOC predicts CWB above and beyond CSE. The results from the present study show that work LOC interacts with work stressors in predicting CWB even after controlling for general LOC. This represents a robust finding, but if significant results were found for work LOC above and beyond CSE, the findings would prove to be even more substantial and suggest work LOC as a very important variable in the prediction of CWB.

\section{Conclusions}

CWB has detrimental effects on organizations and the people associated with the organization; as such, organizations must be aware of potential factors that influence employee engagement in CWB. This study provides initial evidence of work LOC as an important variable to consider with regard to CWB; work LOC demonstrated main effects with CWB, as well as interactive affects with work stressors in predicting CWB even after controlling for general LOC. Given that some of the results of this study are counterintuitive and diverge from previous studies, future research is encouraged to fully understand work LOC's role in predicting CWB. 


\section{REFERENCES}

Adams, J.S. (1963). Toward an understanding of inequity. Journal of Abnormal and Social Psychology, 67, 422-436.

Allen, V.L., \& Greenberger, D.B. (1980). Destruction and perceived control. In A. Baum, \& J.E. Singer (Eds.), Applications of Personal Control. Hillside, NJ: Earlbaum.

Aiken, L.S., \& West, S.G. (1991). Multiple regression: Testing and interpreting interactions. Newbury Park, CA: Sage.

Andersson, L.M., \& Pearson, C.M. (1999). Tit-for-tat? The spiraling effect of incivility in the workplace. Academy of Management Review, 24(3), 452-71.

Baron, R. M., \& Kenny, D. A. (1986). The moderator-mediator variable distinction in social psychological research: Conceptual, strategic and statistical considerations. Journal of Personality and Social Psychology, 51, 1173-1182.

Bayram, N., Gursakal, N., \& Bilgel, N. (2009). Counterproductive work behavior among whitecollar employees: A study from Turkey. International Journal of Selection and Assessment, 17(2), 180-189.

Bennett, R.J., \& Robinson, S.L. (2000). Development of a measure of workplace deviance. Journal of Applied Psychology, 85(3), 349-360.

Berry, C.M., Ones, D.S., \& Sackett, P.R. (2007). Interpersonal deviance, organizational deviance, and their common correlates: A review and meta-analysis. Journal of Applied Psychology, 92(2), 410-424.

Bowling, N.A., \& Eschleman, K.J. (2010). Employee personality as a moderator of the relationships between work stressors and counterproductive work behavior. Journal of Occupational Health Psychology, 15(1), 91-103. 
Bruk-Lee, V., \& Spector, P.E. (2006). The social stressors-counterproductive work behaviors link: Are conflicts with supervisors and coworkers the same? Journal of Occupational Health Psychology, 11(2), 145-156.

Carver, C.S., Scheier, M.F., \& Weintraub, J.K. (1989). Assessing coping strategies: A theoretically based approach. Journal of Personality and Social Psychology, 56(2), 267283.

Chen, P.Y., \& Spector, P.E. (1992). Relationships of work stressors with aggression, withdrawal, theft and substance use: An exploratory study. Journal of Occupational and Organizational Psychology, 65, 177-184.

Coffin, B. (2003). Breaking the silence on white collar crime. Risk Management, 50(9), 8.

Cohen-Charash, Y., \& Spector, P.E. (2001). The role of justice in organizations: A metaanalysis. Organizational Behavior and Human Decision Processes, 86(2), 278-321.

Cullen, M.J., \& Sackett, P.R. (2003). Personality and counterproductive workplace behavior. In M.R. Barrick \& A.M. Ryan (Eds.), Personality and work: Reconsidering the role of Personality in Organizations (pp.150-182). New York: Jossey-Bass-Pfeiffer.

Dalal, R.S. (2005). A meta-analysis of the relationship between organizational citizenship behavior and counterproductive work behavior. Journal of Applied Psychology, 90(6), $1241-1255$.

DeNeve, K.M., \& Cooper, H. (1998). The happy personality: A meta-analysis of 137 personality traits and subjective well-being. Psychological Bulletin, 124(2), 197-229.

Evans, M. (1985). A Monte Carlo study of the effects of correlated method variance in moderated multiple regression analysis. Organizational Behavior and Human Decision Processes, 36, 305-323. 
Flaherty, S., \& Moss, S.A. (2007). The impact of personality and team context on the relationship between workplace injustice and counterproductive work behavior. Journal of Applied Social Psychology, 37(11), 2549-2575.

Fox, S., \& Spector, P.E. (1999). A model of work frustration-aggression. Journal of Organizational Behavior, 20, 915-931.

Fox,.S. \& Spector, P.E. (2006). The many roles of control in a stressor-emotion theory of counterproductive work behavior. In P.L. Perrewe \& D.C. Ganster (Eds.), Research in Occupational Stress and Well Being (pp. 171-201). Oxford: Elsevier.

Fox, S., Spector, P.E., Goh, A., \& Bruursema, K. (2007). Does your coworker know what you're doing? Convergence of self and peer-reports of counterproductive work behavior. International Journal of Stress Management, 14, 41-60.

Fox, S., Spector, P.E., \& Miles, D. (2001). Counterproductive work behavior (CWB) in response to job stressors and organizational justice: Some mediator and moderator tests for autonomy and emotions. Journal of Vocational Behavior, 59, 291-309.

Galperin, B.L., \& Burke, R.J. (2006). Uncovering the relationship between workaholism and workplace destructive and constructive deviance: An exploratory study. International Journal of Human Resource Management, 17, 331-347.

Greenberg, J. (1990). Employee theft as a reaction to underpayment inequity: The hidden cost of pay cuts. Journal of Applied Psychology, 75(5), 561-568.

Gruys, M.L., \& Sackett, P.R. (2003). Investigating the dimensionality of counterproductive work behavior. International Journal of Selection and Assessment, 11(1), 30-42. 
Heacox, N.J. (1996). The relationship between organizational frustration and aggressive behaviors in the workplace. Unpublished doctoral dissertation, California School of Professional Psychology, San Diego.

Hepworth, W., \& Towler, A. (2004). The effects of individual differences and charismatic leadership on workplace aggression. Journal of Occupational Health Psychology, 9(2), 176-185.

Hershcovis, M.S., Turner, N., Barling, J., Arnold, K.A., Dupré, K.E., Inness, M., et al. (2007). Predicting workplace aggression: A meta-analysis. Journal of Applied Psychology, 92(1), 228-238.

Hiroto, D.S. (1974). Locus of control and learned helplessness. Journal of Experimental Psychology, 102(2), 187-193.

Hollinger, R.D., \& Clark, J.P. (1983). Theft by employees. Lexington, MA: Lexington Books.

Hough, L.M. (1992). The "big five" personality variables-construct confusion: Description versus prediction. Human Performance, 5(2), 139-155.

Judge, T.A., \& Bono, J.E. (2001). Relationship of core self-evaluation traits - self-esteem, generalized self-efficacy, locus of control, and emotional stability - with job satisfaction and performance: A meta-analysis. Journal of Applied Psychology, 86(1), 80-92.

Judge, T.A., Erez, A., Bono, J.E., Thoresen, C.J. (2003). The core self-evaluations scale: Development of a measure. Personnel Psychology, 56, 303-331.

Lau, V.C., Au, W.T., \& Ho, J.M. (2003). A qualitative and quantitative review of antecedents of counterproductive behavior in organizations. Journal of Business and Psychology, 18(1), 73-99.

LeBreton, J.M., \& Tonidandel, S. (2008). Multivariate relative importance: Extending relative 
weight analysis to multivariate criterion spaces. Journal of Applied Psychology, 93(2), 329-345.

Levenson, H. (1973). Multidimensional locus of control in psychiatric patients. Journal of Consulting and Clinical Psychology, 41, 397-404.

Leventhal, G.S. (1980). What should be done with equity theory? New approaches to the study of fairness in social relationships. In K.S. Gergen, M.S. Greenberg, \& R.H. Willis (Eds.), Social exchange: Advances in theory and research (pp. 27-55). New York: Plenum Press.

Lim, V.K. (2002). The IT way of loafing on the job: Cyberloafing, neutralizing and organizational justice. Journal of Organizational Behavior, 23, 675-694.

Marcus, B., \& Schuler, H. (2004). Antecedents of counterproductive behavior at work: A general perspective. Journal of Applied Psychology, 89(4), 647-660.

McCrae, R.R., \& Costa Jr., P.T. (1987). Validation of the five-factor model of personality across instruments and observers. Journal of Personality and Social Psychology, 52(1), 81-90.

Miles, D.E., Borman, W.E., Spector, P.E., \& Fox S. (2002). Building an integrative model of extra role work behaviors: A comparison of counterproductive work behavior with organizational citizenship behavior. International Journal of Selection and Assessment, $10(2), 51-57$.

Moorman, R.H. (1991). Relationship between organizational justice and organizational citizenship behaviors: Do fairness perceptions influence employee citizenship? Journal of Applied Psychology, 76(6), 845-855. 
Mount, M., Ilies, R., \& Johnson, E. (2006). Relationships of personality traits and counterproductive work behaviors: The mediating effects of job satisfaction. Personnel Psychology, 59, 591-622.

Neuman, J.H., \& Baron, R.A. (1998). Workplace violence and workplace aggression: Evidence concerning specific forms, potential causes, and preferred targets. Journal of Management, 24(3), 391-419.

Oravec, J.A. (2002). Constructive approaches to internet recreation in the workplace. Communications of the ACM, 45(1), 60-63.

Penney, L.M., \& Spector, P.E. (2002). Narcissism and counterproductive work behavior: Do bigger egos mean bigger problems? International Journal of Selection and Assessment, $10(1), 126-134$.

Penney, L.M., \& Spector, P.E. (2005). Job stress, incivility, and counterproductive work behavior (CWB): The moderating role of negative affectivity. Journal of Organizational Behavior, 26, 777-796.

Perlow, R., \& Latham, L.L. (1993). Relationship of client abuse with locus of control and gender: A longitudinal study in mental retardation facilities. Journal of Applied Psychology, 78(5), 831-834.

Peters, L.H., O’Connor, E.J., \& Rudolf, C.J. (1980). The behavioral and affective consequences of performance-relevant situational variables. Organizational Behavior and Human Performance, 25(1), 79-96.

Podsakoff, P.M., MacKenzie, S.B., Lee, J.Y., \& Podsakoff, N.P. (2003). Common method biases in behavioral research: A review of the literature and recommended remedies. Journal of Applied Psychology, 88(5), 879-903. 
Price, J.L., \& Mueller, C.W. (1986). Handbook of organizational measurement. Marshfield, MA: Pittman.

Robinson, S.L., \& Bennett, R.J. (1995). A typology of deviant workplace behaviors: A multidimensional scaling study. Academy of Management Journal, 38(2), 555-572.

Robinson, S.L., O’Leary-Kelly, A.M. (1998). Monkey see, monkey do: The influence of work groups on the antisocial behavior of employees. Academy of Management Journal, 41(6), 658-672.

Rotter, J.B. (1990). Internal versus external control of reinforcement: A case history of a variable. American Psychologist, 45(4), 489-493.

Rotundo, N., \& Spector, P.E. (2010). Counterproductive work behavior and withdrawal. In J.L. Farr \& N.T. Tippens (Eds.), Handbook of Employee Selection (pp.489-511). Routledge: Taylor \& Francis.

Sackett, P.R. (2002). The structure of counterproductive work behaviors: Dimensionality and relationships with facets of job performance. International Journal of Selection and Assessment, 10, 5-11.

Salgado, J.F. (2002). The big five personality dimensions and counterproductive behaviors. International Journal of Selection and Assessment, 10(2), 117-125.

Sandler, I.N., \& Lakey, B. (1982). Locus of control as a stress moderator: The role of control perceptions and social support. American Journal of Community Psychology, 10(1), 6580.

Sapp, S.G., \& Harrod, W.J. (1993). Reliability and validity of a brief version of Levenson's locus of control scale. Psychological Reports, 72(2), 539-550. 
Skarlicki, D.P., \& Folger, R. (1997). Retaliation in the workplace: The roles of distributive, procedural, and interactional justice. Journal of Applied Psychology, 82(3), 434-443.

Sonnentag, S., \& Frese, M. (2003). Stress in organizations. In W. Borman, D. Ilgen, \& R. Klimoski (Eds.), Handbook of psychology: Vol. 12. Industrial and organizational psychology (pp. 453-492). Hoboken, NJ: John Wiley \& Sons, Inc.

Spector, P.E. (1998). A control model of the job stress process. In C.L. Cooper (Ed.), Theories of Organizational Stress (pp. 153-169). London: Oxford University Press.

Spector, P.E. (1982). Behavior in organizations as a function of employee's locus of control. Psychological Bulletin, 91(3), 482-497.

Spector, P.E. (1988). Development of the work locus of control scale. Journal of Occupational Psychology, 61(4), 335-340.

Spector, P.E. (2006). Method variance in organizational research: Truth or urban legend? Organizational Research Methods, 9, 221-232.

Spector, P.E., Cooper, C.L., Sanchez, J.I., O’Driscoll, M., Sparks, K., Bernin, P., ...Yu, S. (2002). Locus of control and well-being at work: How generalizable are Western findings? Academy of Management Journal, 45(2), 453-466.

Spector, P.E., \& Fox, S. (2002). An emotion-centered model of voluntary work behavior: Some parallels between counterproductive work behavior and organizational citizenship behavior. Human Resource Management Review, 12, 269-292.

Spector, P.E., \& Fox, S. (2003). Reducing subjectivity in the assessment of the job environment: Development of the Factual Autonomy Scale (FAS). Journal of Organizational Behavior, $24,417-432$. 
Spector, P.E., Fox, S., Penney, L.M., Bruursema, K., Goh, A., \& Kessler, S. (2006). The dimensionality of counterproductivity: Are all counterproductive behaviors created equal? Journal of Vocational Behavior, 68, 446-460.

Spector, P.E., \& Jex, S.M. (1998). Development of four self-report measures of job stressors and strain: Interpersonal conflict at work scale, organizational constraints scale, quantitative workload inventory, and physical symptoms inventory. Journal of Occupational Health Psychology, 3(4), 356-367.

Stanton, J.M., \& Weiss, E.M. (2002). Online panels for social science research: An introduction to the StudyResponse project (Technical report no. 13001; www.Studyresponse.com). Syracuse, NY; Syracuse University School of Information Studies.

Storms, P.L., \& Spector, P.E. (1987). Relationships of organizational frustration with reported behavioral reactions: The moderating effect of locus of control. Journal of Occupational Psychology, 60, 227-234.

Tellegen, A. (1991). Personality traits: Issues of definition, evidence and assessment. In D. Cicchetti \& W. Grove (Eds.), Thinking clearly about psychology: Essays In honor of Paul Everett Meehl. Minneapolis: University of Minnesota Press.

Tepper, B.J. (2007). Abusive supervision in work organizations: Review, synthesis, and research agenda. Journal of Management, 33(3), 261-289.

Verton, D. (2000). Employers OK with e-surfing. Computerworld, 54, 51.

Wallhagen, M.I., Strawbridge, W.J., Kaplan, G.A., \& Cohen, R.D. (1994). Impact of internal locus of control on health outcomes for older men and women: A longitudinal perspective. The Gerontologist, 34(3), 299-306. 
Watson, D., Clark, L.A., \& Tellegen, A. (1988). Development and validation of brief measures of positive and negative affect: The PANAS scales. Journal of Personality and Social Psychology, 54(6), 1063-1070.

Weiss, H.M., \& Cropanzano, R. (1996). Affective events theory: A theoretical discussion of the structure, causes and consequences of affective experiences at work. Research in Organizational Behavior, 18, 1-74. 


\section{APPENDIX A: MEASURES}

A. Organizational Constraints Scale (Spector \& Jex, 1998)

How often do you find it difficult or impossible to do your job because of ...?

1. Poor equipment or supplies.

2. Organizational rules and procedures.

3. Other employees.

4. You supervisor.

5. Lack of equipment or supplies.

6 . Inadequate training.

7. Interruptions by other people.

8. Lack of necessary information about what to do or how to do it.

9. Conflicting job demands.

10. Inadequate help from others.

11. Incorrect instructions.

Less than once per month or never $=1$

Once or twice per month $=2$

Once or twice per week $=3$

Once or twice per day $=4$

Several times per day $=5$

B. Interpersonal Conflict (Specor \& Jex, 1998).

Please answer the following questions using the answer scale below:

1. How often do you get into arguments with others at work?

2. How often do other people yell at you at work?

3 . How often are people rude to you at work?

4. How often do other people do nasty things to you at work?

Never $=1$

Rarely $=2$

Sometimes $=3$

Quite Often $=4$

Very Often $=5$

C. Quantitative Workload Inventory (Spector \& Jex, 1998)

Please answer the following questions using the answer scale below:

1. How often does your job require you to work very fast?

2. How often does your job require you to work very hard?

3. How often does your job leave you with little time to get things done?

4. How often is there a great deal to be done? 
5. How often do you have to do more work than you can do well?

Less than once per month or never $=1$

Once or twice per month $=2$

Once or twice per week $=3$

Once or twice per day $=4$

Several times per day $=5$

D. Organizational Justice (Moorman, 1991)

The purpose of this survey is to examine your perceptions about workplace equity. In answering the following questions, think about the day-to-day decisions made about worker responsibilities, schedules, rewards, and general treatment. Use the following scale to indicate the extent to which you agree or disagree with each statement.

Procedural/Interactional Justice

When decisions about other employees in general or you in particular are made in this company...

... requests for clarification and additional information are allowed.

... you are treated with respect and dignity.

... you are dealt with in a truthful manner.

$\ldots$ all the sides affected by the decisions are represented.

... the decisions are applied with consistency to the parties affected.

... you are offered adequate justification for the decisions.

... accurate information upon which the decisions are based is collected.

... complete information upon which the decisions are based is collected.

... opportunities are provided to appeal or challenge the decisions.

... you are treated with kindness and consideration.

... you are shown concern for your rights as an employee.

... you are helped to understand the reasons for the decision.

Strongly Disagree $=1$

Slightly Disagree $=2$

Neither Agree nor Disagree $=3$

Slightly Agree $=4$

Strongly Agree $=5$

Distributive Justice

To what extent are you fairly rewarded...

... considering the responsibilities that you have.

... taking into account the amount of education and training that you have had.

... in view of the amount of experience that you have.

... for the amount of effort that you put forth. 
... for the work that you have done well.

_ $\ldots$ for the stresses and strains of your job.

Very Unfairly $=1$

Unfairly $=2$

Undecided $=3$

Fairly $=4$

Very Fairly $=5$

E. Work Locus of Control Scale (short form) (Spector, 1988)

The following questions concern your beliefs about jobs in general. They do not refer only to your present job. Please answer the following questions using the answer scale below:

1. On most jobs, people can pretty much accomplish whatever they set out to accomplish

2. If you know what you want out of a job, you can find a job that gives it to you

3. Getting the job you want is mostly a matter of luck

4. Promotions are usually a matter of good fortune

5. Promotions are given to employees who perform well on the job

6. It takes a lot of luck to be an outstanding employee on most jobs

7. People who perform their jobs well generally get rewarded

8. The main difference between people who make a lot of money and people who make a little money is luck

Disagree very much $=1$

Disagree moderately $=2$

Disagree slightly $=3$

Agree slightly $=4$

Agree moderately $=5$

Agree very much $=6$

F. Counterproductive Work Behavior (Spector, Fox, Penney, Bruursema, Goh, \& Kessler, 2006)

How often have you done each of the following things on your present job?

1. Purposely wasted your employer's materials/supplies

2. Told people outside the job what a lousy place you work for

3. Purposely did your work incorrectly

4. Came to work late without permission

5. Stayed home from work and said you were sick when you weren't

6. Purposely damaged a piece of equipment or property

7. Purposely dirtied or littered your place of work

8. Stolen something belonging to your employer

9. Started or continued a damaging or harmful rumor at work

10 . Been nasty or rude to a client or customer

11. Purposely worked slowly when things needed to get done

12. Taken a longer break than you were allowed to take 
13. Purposely failed to follow instructions

14. Left work earlier than you were allowed to

15. Insulted someone about their job performance

16. Made fun of someone's personal life

17. Took supplies or tools home without permission

18. Put in to be paid for more hours than you worked

19. Took money from your employer without permission

20. Ignored someone at work

21. Blamed someone at work for error you made

22. Started an argument with someone at work

23. Stole something belonging to someone at work

24 . Verbally abused someone at work

25. Made an obscene gesture (the finger) to someone at work

26. Threatened someone at work with violence

27. Threatened someone at work, but not physically

28. Said something obscene to someone at work to make them feel bad

29. Did something to make someone at work look bad

30. Played a mean prank to embarrass someone at work

31. Looked at someone at work's private mail/property without permission

32. Hit or pushed someone at work

33. Insulted or made fun of someone at work

Never $=1$

Once or Twice $=2$

Once or Twice per month $=3$

Once or Twice per week $=4$

Every day $=5$

G. Negative Affect Schedule (Watson, Clark, \& Tellegen, 1988)

This scale consists of a number of words that describe different feelings and emotions. Read each item and then mark the appropriate answer in the space next to the word. Indicate to what extent you generally feel this way, that is, how you feel on average. Use the following scale to record your answers.

\begin{tabular}{ll} 
& Scared \\
\hline Afraid \\
\hline Upset \\
Distressed \\
\hline$\quad$ Jittery \\
Nervous \\
Ashamed \\
\hline$\quad$ Guilty \\
\hline$\quad$ Irritable \\
\hline$\quad$ Hostile
\end{tabular}


Very slightly or not at all $=1$

A little $=2$

Moderately $=3$

Quite a bit $=4$

Extremely $=5$

H. Frustration (Peters, O’Connor, \& Rudolf, 1980)

Please rate the extent to which you agree/disagree with the following statements

1. Trying to get my job done is a very frustrating experience

2. Being frustrated comes with the job

3. Overall, I experience very little frustration on this job

Strongly Disagree $=1$

Disagree $=2$

Slightly Disagree $=3$

Slightly Agree $=4$

Agree $=5$

Strongly Agree $=6$

I. General Locus of Control (Sapp \& Harrod, 1993)

Please rate the extent to which you agree/disagree with the following statements

1. To a great extent, my life is controlled by accidental happenings

2. I feel like what happens in my life is mostly determined by powerful people

3. Often there is no chance of protecting my personal interests from bad luck happenings

4. When I get what I want, it is usually because I am lucky

5. My life is chiefly controlled by powerful others

6. People like myself have very little chance of protecting our personal interests when they conflict with those of strong pressure groups

7. I can pretty much determine what will happen in my life

8. I am usually able to protect my personal interests

9. My life is determined by my own actions

Strongly Disagree $=1$

Disagree $=2$

Slightly Disagree $=3$

Slightly Agree = 4

Agree $=5$

Strongly Agree $=6$ 


\section{APPENDIX B: HSRB FORM}

\section{BGSU \\ Bowling Green State University}

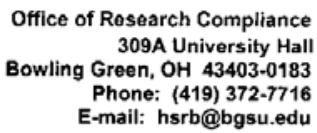

ISRB MEMBERSHII

$$
\text { 2010-2011 }
$$

.my Morgan, HSRB Chair inesiology

morganøbgsu.edu

fary Hare, HSRB Vice Chair sychology

llharẹbgsu.edu

1. Wayne Bell, M.D rood Health Corp.

53-6225

seakingdocodacor,net

heryl Conley

Theimer's Assn, NW Ohio onleycergsu.edu

. Fleming Falion, Jr., M.D. ublic \& Allied Health altonobsu.edu

odney Gabe omm. Sciences \& Disorders gabelebgsu,edu

illary Harms iffice of Research Compliance srbøbgsu.edu

esa Lockford heatre \& Film ckflo@bgsu.edu

Iontana Miller opular Culture iontanm@bgsu.edu

:anne Novak itervention Services ıvak@bgsu.edu

rin Smith

sychology

imithobgsu,edu

shulosh Solıni

amily and Consumer Science isohonebssu,edu

Iarie Tisak

sychology

tisak@bgsu.cdu
March 25, 2011

TO: $\quad$ Justin Sprung

Psychology

FROM: Hillary Harms, Ph.D. HSRB Administrator

RE: HSRB Project No.: H11T185GE7

TITLE: $\quad$ Work Locus of Control as a Moderator of the Relationship between Work Stressors and Counterproductive Work Behavior

You have met the conditions for approval for your project involving human subjects. As of March 24, 2011, your project has been granted final approval by the Human Subjects Review Board (HSRB). This approval expires on March 15, 2012. You may proceed with subject recruitment and data collection.

The final approved version of the consent document(s) is attached. Consistent with federal OHRP guidance to IRBs, the consent document(s) bearing the HSRB approval/expiration date stamp is the only valid version and you must use copies of the date-stamped document(s) in obtaining consent from research subjects.

You are responsible to conduct the study as approved by the HSRB and to use only approved forms. If you seek to make any changes in your project activities or procedures, send a request for modifications to the HSRB via this office. Those changes must be approved by the HSRB prior to their implementation.

You have been approved to enroll 150 participants. If you want to enroll additional participants you must seek approval from the HSRB.

Good luck with your work. Let me know if this office or the HSRB can be of assistance as your project proceeds.

\section{Comments/ Modifications:}

Please add text equivalent to the HSRB approval/expiration date stamp to the "footer" area of the electronic consent form (see attached for specific text).

c: Dr. Steve Jex

Research Category: EXPEDITED $\# 7$ 


\section{Consent Form}

The purpose of this study is to examine the relationship between work stressors, perceptions of control, and counterproductive work behavior. This study will be a benefit to you because a better understanding of this area of research can potentially lead to organizational interventions to help employers develop strategies to lessen the negative effects of work stressors. It may also provide an opportunity for self-reflection on how you respond to stressful work situations. Those who participate will receive a $\$ 5$ incentive in return for your time and effort.

In this study, you will be asked to answer several questions about yourself and your work situation. It will take approximately 20 minutes to finish the survey. This is an anonymous study; no identifying information will be attached to your answers besides your Study Response ID, which will not be linked to your responses after the survey is completed. Your incentive will be administered through the Study Response team according to your ID number. Thus, your answers are not connected to your ID and the people administering the incentives are not allowed to view the data collected for this study. Additionally, the researchers will not have access to your ID numbers. Therefore, your responses will remain anonymous. Additionally, all information provided in the survey will remain confidential. Only the BGSU research team will have access to your answers and only aggregate data will be reported in the results. All data files will be stored in a password-protected file on a computer within a locked office.

Your participation in this study is completely voluntary, and you may refrain from answering any or all questions without penalty or explanation. You are free to withdraw consent and to discontinue participation in this study at any time. Your decision to participate, or not participate, will not affect your relationship to Bowling Green State University.

If you have any questions or comments regarding this study, you can contact Justin Sprung, the principal investigator, at jsprung@bgsu.edu or (419) 372-4397. You can also contact Dr. Steve Jex, the project advisor, at sjex@bgsu.edu or (419) 372-2132. If you have questions about the conduct of this study or your rights as a research participant, you may contact the Chair of Bowling Green State University's Human Subjects Review Board at (419) 372-7716 or hsrb@bgsu.edu

Please click "I Agree" if you wish to participate, indicating that you have read through this form and give your consent to participate in this study. 
Table 1. Proposed Hypotheses

Hypothesis

H1. Work stressors (interpersonal conflict, organizational constraints, organizational injustice, \& workload) will be positively related to measures of CWB: As selfreported work stressors increase, self-reported CWB-I and CWB-O will increase

H2. a: Measures of interpersonal conflict will be more strongly associated with self-reported CWB-I than CWB-O

b: Measures of organizational constraints, organizational injustice, and workload will be more strongly associated with self-reported CWB-O than CWB-I

H3. Higher scores on the Work Locus of Control Scale (external orientation) will be associated with an increase in self-reported CWB-I and CWB-O

H 4. Work locus of control will moderate the relationship between organizational frustration and CWB: organizational frustration will have a greater influence on CWB for those with higher scores on the Work Locus of Control scale (externals) than those with low scores (internals)

H5. Work locus of control will moderate the relationships between work stressors and CWB: Work stressors will have a greater influence on CWB for those with higher scores on the Work Locus of Control scale (externals) than those with low scores (internals) 
Table 2. Descriptive Statistics and Internal Consistencies

\begin{tabular}{llllcc}
\hline Variable & Mean & SD & $\begin{array}{l}\text { Observed } \\
\text { Range }\end{array}$ & $\begin{array}{l}\text { Possible } \\
\text { Range }\end{array}$ & Alpha \\
\hline Age & 39.24 & 10.38 & $20-67$ & - & - \\
Tenure (months) & 8.5 & 6.3 & $1-462$ & - & - \\
Negative Affectivity & 1.84 & .95 & $1-4.7$ & $1-5$ & .95 \\
Organizational Constraints & 2.23 & .93 & $1-4.6$ & $1-5$ & .93 \\
Interpersonal Conflict & 2.10 & 1.12 & $1-5$ & $1-5$ & .94 \\
Workload & 3.24 & 1.02 & $1-5$ & $1-5$ & .89 \\
Organizational Justice & 3.58 & .88 & $1.1-5$ & $1-5$ & .96 \\
Work Locus of Control & 3.06 & .74 & $1-5.5$ & $1-6$ & .72 \\
General Locus of Control & 3.05 & .89 & $1-4.6$ & $1-6$ & .85 \\
CWB-I & 1.67 & 1.06 & $1-4.7$ & $1-5$ & .99 \\
CWB-O & 1.82 & 1.07 & $1-4.8$ & $1-5$ & .98 \\
CWB & 1.74 & 1.05 & $1-4.7$ & $1-5$ & .99 \\
Organizational Frustration & 3.41 & 1.10 & $1-6$ & $1-6$ & .64 \\
\hline
\end{tabular}

Note. $n=208(53 \%$ male $)$ 
Table 3. Intercorrelations among Variables

\begin{tabular}{|c|c|c|c|c|c|c|c|c|c|c|c|c|c|c|}
\hline Variable & 1 & 2 & 3 & 4 & 5 & 6 & 7 & 8 & 9 & 10 & 11 & 12 & 13 & 14 \\
\hline 1. Age & -- & & & & & & & & & & & & & \\
\hline 2. Sex & $.18^{* *}$ & -- & & & & & & & & & & & & \\
\hline 3. Tenure & $.45^{* *}$ & .11 & -- & & & & & & & & & & & \\
\hline 4. NA & $-.22 * *$ & -.08 & $-.19 * *$ & -- & & & & & & & & & & \\
\hline 5. Org. Constraints & $-.20 * *$ & -.08 & $-.21 * *$ & $.59 * *$ & -- & & & & & & & & & \\
\hline 6. Int. Conflict & $-.30 * *$ & $-.19 * *$ & $-.15 *$ & $.63 * *$ & $.73 * *$ & -- & & & & & & & & \\
\hline 7. Workload & -.09 & .00 & -.10 & .14 & $.44 * *$ & $.25^{* *}$ & -- & & & & & & & \\
\hline 8. Org. Justice & $-.20 * *$ & $-.20 * *$ & .08 & -.13 & $-.22 * *$ & -.06 & -.04 & -- & & & & & & \\
\hline 9. Work LOC & $-.23 * *$ & -.10 & -.12 & $.33^{* *}$ & $.37 * *$ & $.41 * *$ & .10 & $-.31 * *$ & -- & & & & & \\
\hline 10. General LOC & $-.28 * *$ & -.12 & -.06 & $.43^{* *}$ & $.42 * *$ & $.53 * *$ & $.18 * *$ & -.10 & $.67 * *$ & -- & & & & \\
\hline 11. CWB-I & $-.25 * *$ & $-.21 * *$ & -.12 & $.61^{* *}$ & $.63 * *$ & $.84 * *$ & $.19 * *$ & $.14^{*}$ & $.36 * *$ & $.51 * *$ & -- & & & \\
\hline 12. CWB-O & $-.28 * *$ & $-.18 * *$ & -.13 & $.60 * *$ & $.63^{* *}$ & $.82 * *$ & $.18^{* *}$ & .11 & $.37 * *$ & $.52 * *$ & $.95^{* *}$ & -- & & \\
\hline 13. CWB & $-.27 * *$ & $-.20 * *$ & -.13 & $.61 * *$ & $.64 * *$ & $.84 * *$ & $.19 * *$ & .13 & $.37 * *$ & $.52 * *$ & $.99 * *$ & $.99 * *$ & -- & \\
\hline 14. Org. Frustration & -.09 & .04 & -.01 & $.37 * *$ & $.54 * *$ & $.39 * *$ & $.36 * *$ & $-.37 * *$ & $.40 * *$ & $.43 * *$ & $.28 * *$ & $.26 * *$ & $.27 * *$ & -- \\
\hline
\end{tabular}

Note. ${ }^{*} p<.05, * * p<.01$ 
Table 4. Moderated Regression Results: Work LOC as a Moderator of the Relationship between Organizational Frustration and CWB

\begin{tabular}{|c|c|c|c|}
\hline Predictors & Step 1 & Step 2 & Step 3 \\
\hline \multicolumn{4}{|l|}{ Step 1} \\
\hline Age & -.01 & -.01 & -.01 \\
\hline Sex & $-.24 *$ & $-.24 *$ & $-.23 *$ \\
\hline Tenure & .00 & .00 & .00 \\
\hline Negative Affectivity & $.52 * *$ & $.53 * *$ & $.53 * *$ \\
\hline General Locus of Control & $.33 * *$ & $.35 * *$ & $.36 * *$ \\
\hline \multicolumn{4}{|l|}{ Step 2} \\
\hline Organizational Frustration & & -.03 & -.02 \\
\hline Work Locus of Control & & -.02 & -.01 \\
\hline \multicolumn{4}{|l|}{ Step 3} \\
\hline \multicolumn{2}{|c|}{ Organizational Frustration * Work Locus of Control } & & .05 \\
\hline$R^{2}$ & .47 & .47 & .47 \\
\hline$\Delta R^{2}$ & & .00 & .00 \\
\hline
\end{tabular}

Note. Regression weights are unstandardized. $* p<.05 . * * p<.01$. 
Table 5. Moderated Regression Results: Work LOC as a Moderator of the Relationship between Organizational Constraints and CWB

\begin{tabular}{|c|c|c|c|}
\hline Predictors & Step 1 & Step 2 & Step 3 \\
\hline \multicolumn{4}{|l|}{ Step 1} \\
\hline Age & -.01 & -.01 & -.01 \\
\hline Sex & $-.24 *$ & $-.23 *$ & -.17 \\
\hline Tenure & .00 & .00 & .00 \\
\hline Negative Affectivity & $.52 * *$ & $.32 * *$ & $.31 * *$ \\
\hline General Locus of Control & $.33^{* *}$ & $.28 * *$ & $.31 * *$ \\
\hline \multicolumn{4}{|l|}{ Step 2} \\
\hline Organizational Constraints & & $.42 * *$ & $.38 * *$ \\
\hline Work Locus of Control & & -.08 & -.02 \\
\hline \multicolumn{4}{|l|}{ Step 3} \\
\hline \multicolumn{2}{|c|}{ Organizational Constraints * Work Locus of Control } & & $.29 * *$ \\
\hline$R^{2}$ & .47 & .55 & .57 \\
\hline$\Delta R^{2}$ & & $.08 * *$ & $.02 * *$ \\
\hline
\end{tabular}

Note. Regression weights are unstandardized. ${ }^{*} p<.05 . * * p<.01$. 
Table 6. Moderated Regression Results: Work LOC as a Moderator of the Relationship between Interpersonal Conflict and CWB

\begin{tabular}{|c|c|c|c|}
\hline Predictors & Step 1 & Step 2 & Step 3 \\
\hline \multicolumn{4}{|l|}{ Step 1} \\
\hline Age & -.01 & .00 & .00 \\
\hline Sex & $-.24 *$ & -.08 & -.08 \\
\hline Tenure & .00 & .00 & .00 \\
\hline Negative Affectivity & $.52 * *$ & $.15^{* *}$ & $.14^{* *}$ \\
\hline General Locus of Control & $.33 * *$ & $.13^{*}$ & $.16^{*}$ \\
\hline \multicolumn{4}{|l|}{ Step 2} \\
\hline Interpersonal Conflict & & $.68 * *$ & $.58 * *$ \\
\hline Work Locus of Control & & -.09 & .04 \\
\hline \multicolumn{4}{|l|}{ Step 3} \\
\hline Interpersonal Conflict $*$ Work Locus of Control & & & $.25 * *$ \\
\hline$R^{2}$ & .47 & .73 & .74 \\
\hline$\Delta R^{2}$ & & $.26^{* *}$ & $.01 * *$ \\
\hline
\end{tabular}

Note. Regression weights are unstandardized. $* p<.05 . * * p<.01$. 
Table 7. Moderated Regression Results: Work LOC as a Moderator of the Relationship between Workload and CWB

\begin{tabular}{|c|c|c|c|}
\hline Predictors & Step 1 & Step 2 & Step 3 \\
\hline \multicolumn{4}{|l|}{ Step 1} \\
\hline Age & -.01 & -.01 & -.01 \\
\hline Sex & $-.24 *$ & $-.25^{*}$ & $-.24 *$ \\
\hline Tenure & .00 & .00 & .00 \\
\hline Negative Affectivity & $.52 * *$ & $.52 * *$ & $.52 * *$ \\
\hline General Locus of Control & $.33 * *$ & $.33 * *$ & $.32 * *$ \\
\hline \multicolumn{4}{|l|}{ Step 2} \\
\hline Workload & & .08 & .07 \\
\hline Work Locus of Control & & -.02 & -.01 \\
\hline \multicolumn{4}{|l|}{ Step 3} \\
\hline Workload $*$ Work Locus of Control & & & .11 \\
\hline$R^{2}$ & .47 & .47 & .48 \\
\hline$\Delta R^{2}$ & & .00 & .01 \\
\hline
\end{tabular}

Note. Regression weights are unstandardized. $* p<.05 . * * p<.01$. 
Table 8. Moderated Regression Results: Work LOC as a Moderator of the Relationship between Organizational Justice and CWB

\begin{tabular}{|c|c|c|c|}
\hline Predictors & Step 1 & Step 2 & Step 3 \\
\hline \multicolumn{4}{|l|}{ Step 1} \\
\hline Age & -.01 & -.01 & -.01 \\
\hline Sex & $-.24 *$ & -.15 & -.16 \\
\hline Tenure & .00 & .00 & .00 \\
\hline Negative Affectivity & $.52 * *$ & $.54 * *$ & $.55^{* *}$ \\
\hline General Locus of Control & $.33 * *$ & $.31 * *$ & $.26 * *$ \\
\hline \multicolumn{4}{|l|}{ Step 2} \\
\hline Organizational Justice & & $.19 * *$ & $.26^{* *}$ \\
\hline Work Locus of Control & & .10 & .04 \\
\hline \multicolumn{4}{|l|}{ Step 3} \\
\hline Organizational Justice $*$ Work Locus of Contro & & & $.15^{*}$ \\
\hline$R^{2}$ & .47 & .50 & .52 \\
\hline$\Delta R^{2}$ & & $.03 * *$ & $.02 *$ \\
\hline
\end{tabular}

Note. Regression weights are unstandardized. ${ }^{*} p<.05 . * * p<.01$. 
Figure 1. Proposed model.

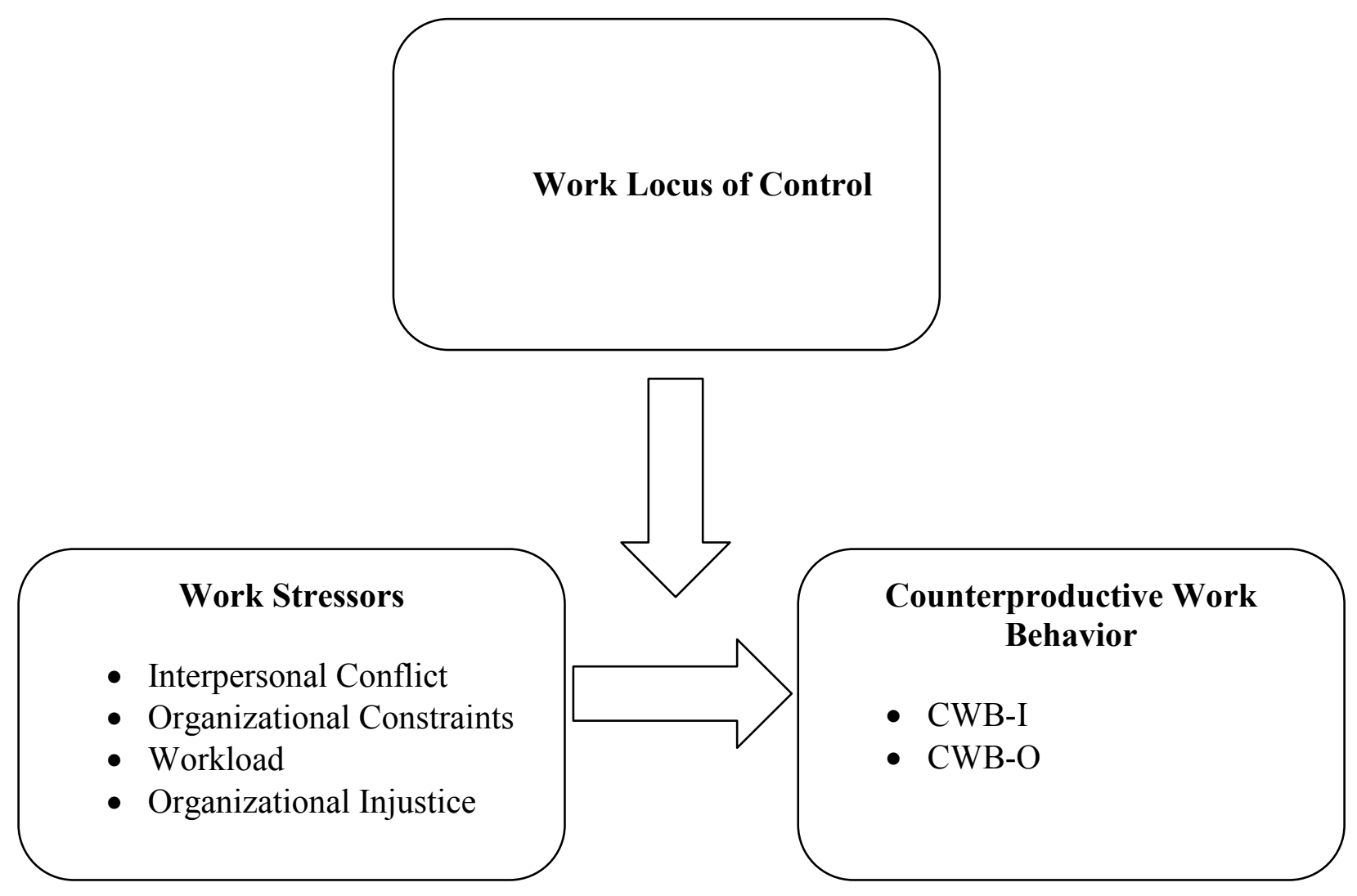


Figure 2. The moderating effect of work locus of control on the relationship between organizational constraints and counterproductive work behavior.

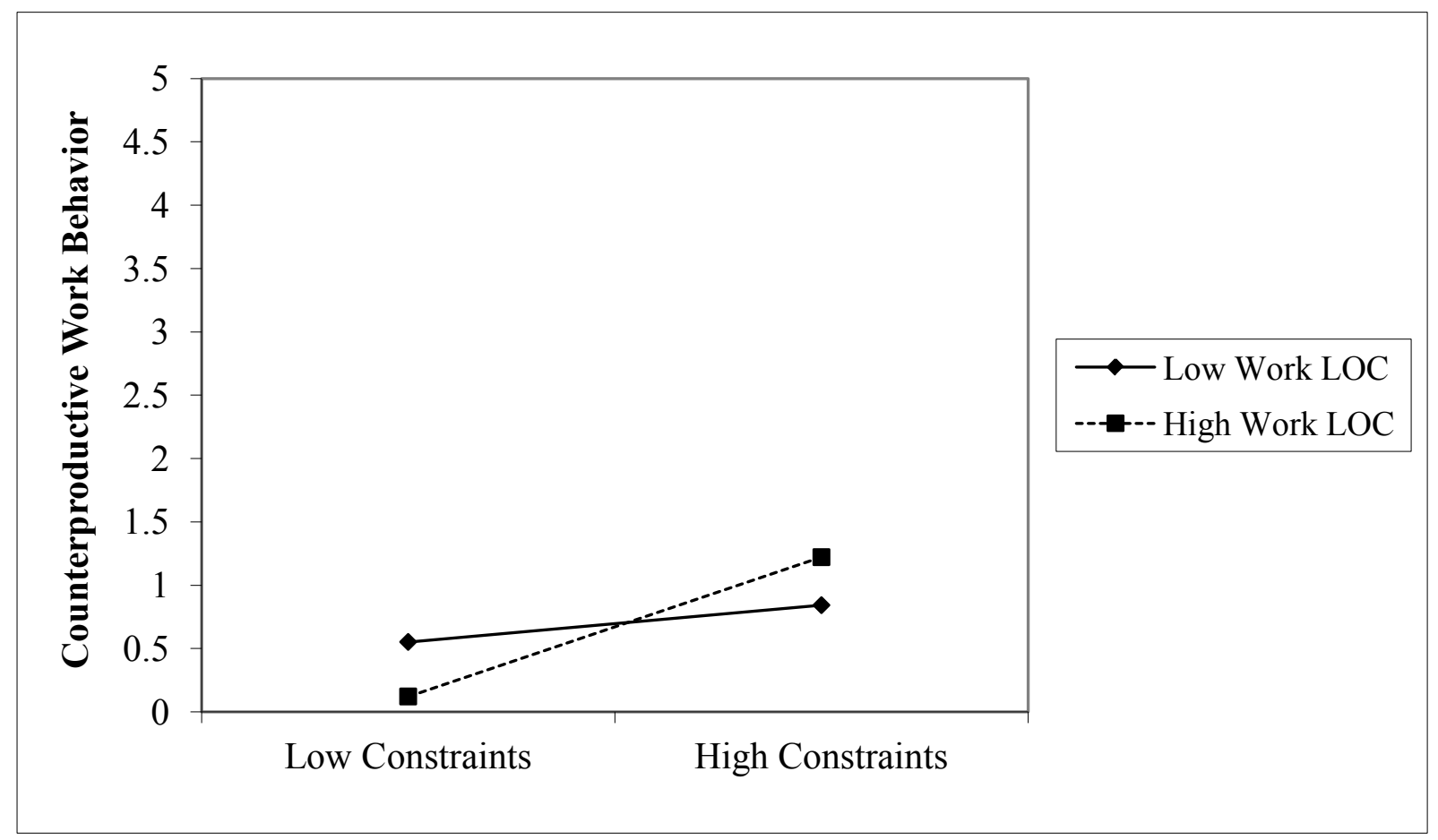

Note. High work $\mathrm{LOC}=$ external orientation. 
Figure 3. The moderating effect of work locus of control on the relationship between interpersonal conflict and counterproductive work behavior.

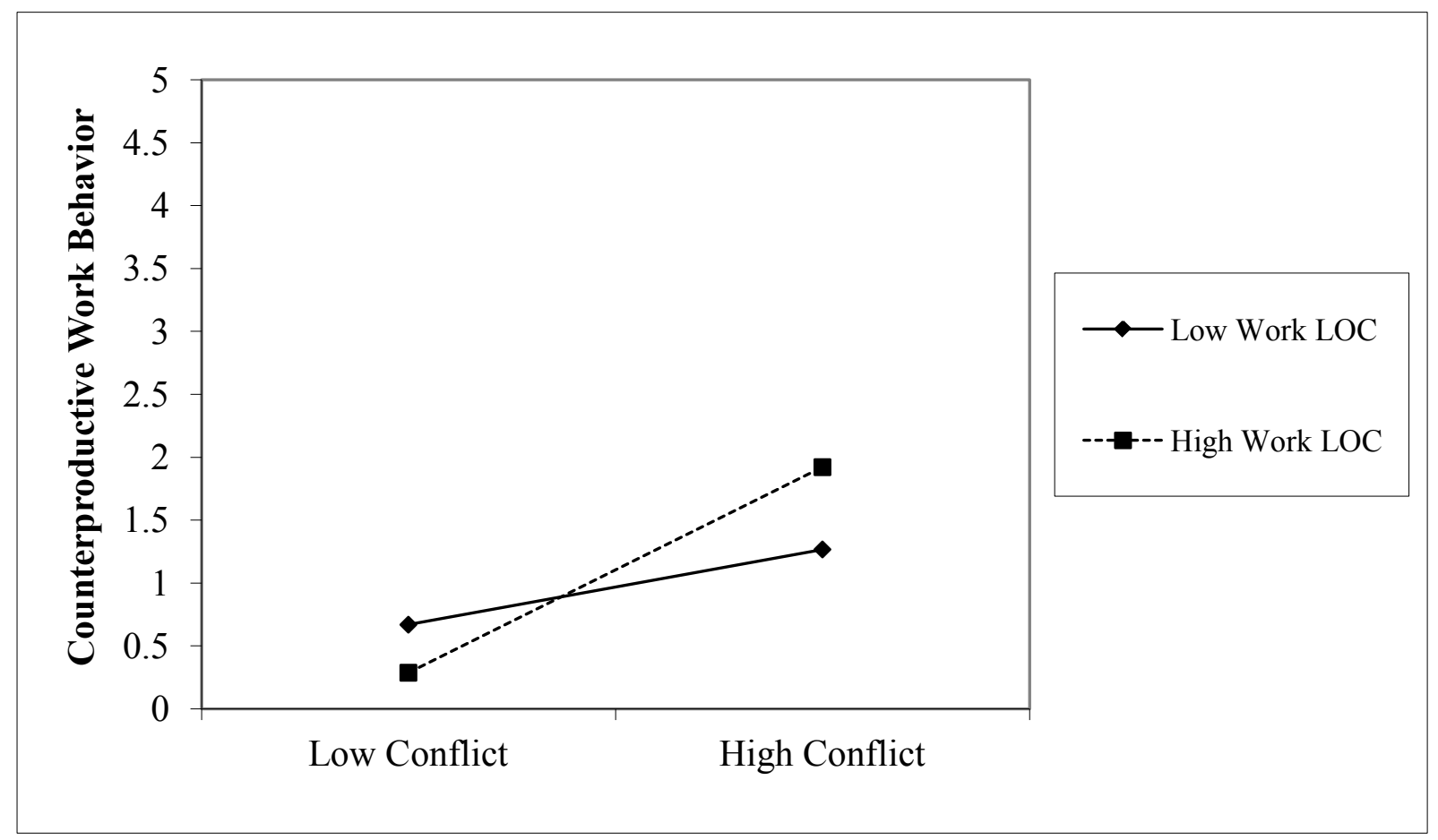

Note. High work LOC $=$ external orientation. 
Figure 4. The moderating effect of work locus of control on the relationship between organizational justice and counterproductive work behavior.

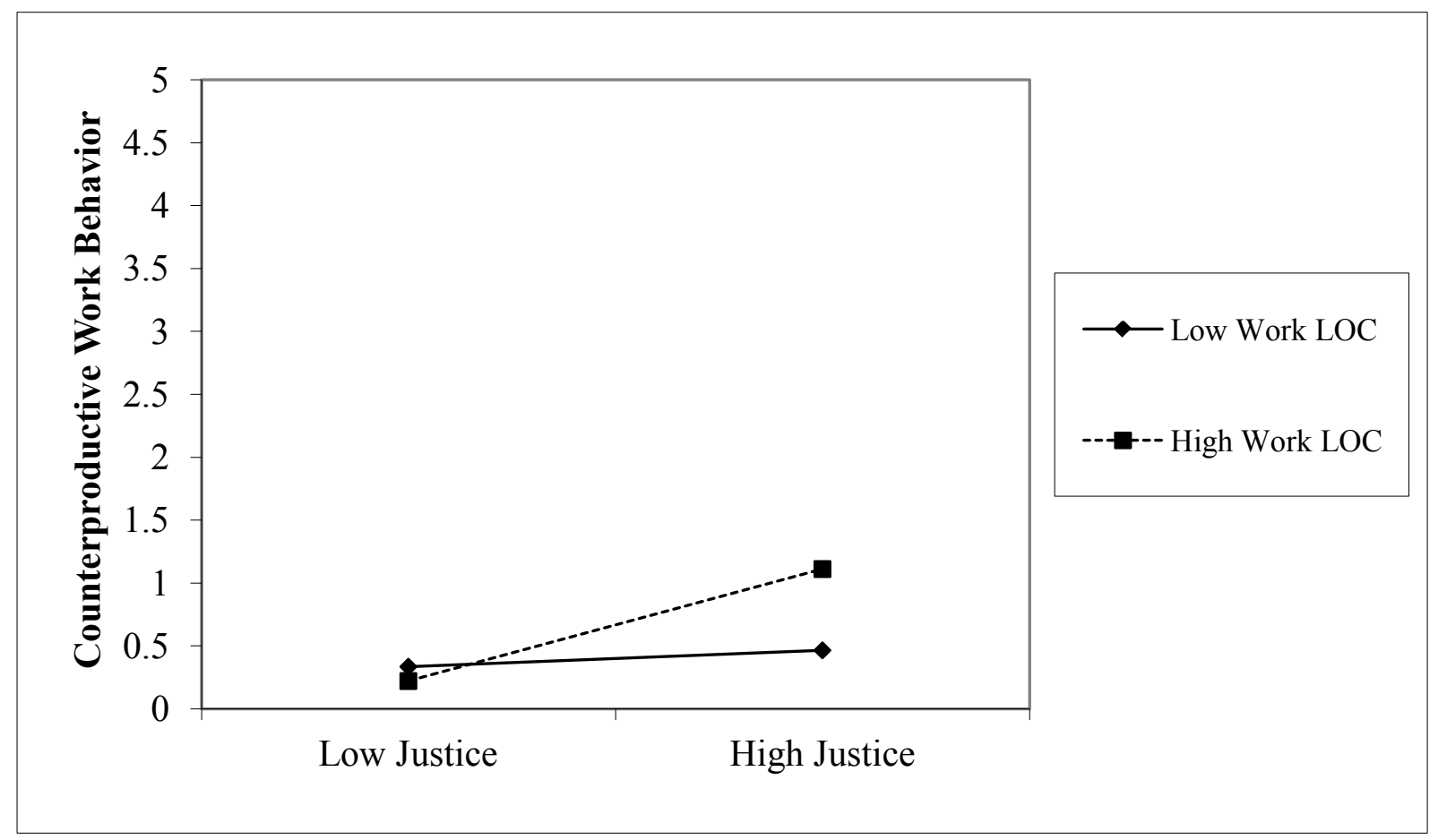

Note. High work LOC = external orientation. 